\title{
Turbulence characteristics in grassland canopies and implications for tracer transport
}

\author{
E. Nemitz ${ }^{1}$, B. Loubet ${ }^{2}$, B. E. Lehmann ${ }^{3, \dagger}$, P. Cellier ${ }^{2}$, A. Neftel ${ }^{4}$, S. K. Jones ${ }^{1,4}$, A. Hensen ${ }^{5}$, B. Ihly ${ }^{3,6}$, \\ S. V. Tarakanov ${ }^{6}$, and M. A. Sutton ${ }^{1}$ \\ ${ }^{1}$ Centre for Ecology and Hydrology (CEH), Edinburgh, Bush Estate, Penicuik, Midlothian, EH26 0QB, UK \\ ${ }^{2}$ Institut National de la Recherche Agronomique (INRA), UMR Environnement et Grandes Cultures, \\ 78850 Thiverval-Grignon, France \\ ${ }^{3}$ Institute of Physics, University of Berne, Switzerland \\ ${ }^{4}$ Agroscope Reckenholz-Tänikon Research Station ART, 8046 Zurich, Switzerland \\ ${ }^{5}$ Energy Centre of the Netherlands (ECN), Petten, The Netherlands \\ ${ }^{6}$ Institute of Silicate Chemistry, St. Petersburg, Russia \\ ${ }^{\dagger}$ This paper is dedicated to Bernhard Lehmann who sadly passed away during the analysis of this dataset
}

Received: 21 October 2008 - Published in Biogeosciences Discuss.: 8 January 2009

Revised: 20 April 2009 - Accepted: 6 May 2009 - Published: 7 August 2009

\begin{abstract}
In-canopy turbulence is a required input to study pollutant cycling and chemistry within plant canopies and to link concentrations and sources. Despite the importance of grasslands worldwide, most previous work has focused on forests and crops. Here, turbulence parameters in a mature agricultural grassland canopy were measured with a combination of a small ultrasonic anemometer, hotwire anemometry and a radon $(\mathrm{Rn})$ tracer technique, as part of a measurement to study ammonia $\left(\mathrm{NH}_{3}\right)$ exchange with grassland. The measurements are used to derive vertical profiles of basic turbulent parameters, for quadrant-hole analysis of the two-parametric frequency distributions of $u^{\prime}-w^{\prime}$ and to derive in-canopy eddy diffusivities as input for models of incanopy tracer transport. The results are in line with previous measurements on taller canopies, but shows increased decoupling between in-canopy flow and above-canopy turbulence. The comparison of sonic anemometry and Rn measurements implies that Lagrangian time-scales must decrease sharply at the ground, with important implications for estimating the magnitude of ground-level and soil emissions from concentration measurements. Atmospheric stability above and within the canopy has little influence on the standard deviation of vertical wind component inside the canopy. Use of the turbulence parameters in an analytical Lagrangian frame-
\end{abstract}

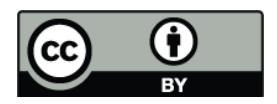

Correspondence to: E. Nemitz (en@ceh.ac.uk) work, which is here validated for heat transfer, suggests that measured in-canopy profiles of $\mathrm{NH}_{3}$ are consistent with a ground-level source, presumably from senescent plant parts, which is recaptured by the overlying canopy.

\section{Introduction}

Atmospheric turbulence well above flat, homogenous terrain is reasonably well understood. By comparison, little is known about the properties of turbulence within plant canopies. In-canopy turbulence impacts on biogeochemical cycling processes, e.g., the fraction of pollutants that are released by a part of the canopy and re-captured by another vs. the fraction that escapes the canopy (e.g., Nemitz et al., 2000a; Denmead et al., 2008). In addition, by governing the residence time and gradients of pollutants inside the canopy, it controls the time available for in-canopy chemical transformations. Similarly, in-canopy turbulence controls the mixing of substances from the atmosphere into the canopy air space, which may be required for the chemical reaction to proceed (e.g. oxidants such as ozone). For example, this is relevant to estimate the fraction of soil $\mathrm{NO}$ emissions that is converted to $\mathrm{NO}_{2}$ within the canopy and taken up by overlying vegetation. Similarly, several studies have attempted to quantify the fraction of biogenic volatile organic compounds (BVOCs) emission that reacts within plant canopies to gaseous oxidation products and particles and is therefore

Published by Copernicus Publications on behalf of the European Geosciences Union. 
not captured by above-canopy flux measurements. For example, 10 to $40 \%$ of isoprene has been estimated to be converted mainly to methyl vinyl ketone and methacrolein below a typical measurement height above forests (e.g. Makar et al., 1999; Stroud et al., 2005, Rinne et al., 2007). Micrometeorological flux measurements of sesquiterpene underestimate surface emissions even more, as the largest fraction of these highly reactive compounds may react within the canopy (e.g. Ciccioli et al., 1999). A similar process is likely to affect flux measurements of ammonia $\left(\mathrm{NH}_{3}\right)$, which may react with atmospheric acids within the canopy where time-scales for turbulent transport are long, even if a time-scale analysis above the canopy suggests that chemistry would be too slow (e.g. Nemitz and Sutton, 2004).

Information on in-canopy turbulence is also needed for a new generation of vertically resolved footprint models, which attempt to link canopy-scale fluxes measured above vegetation to their source area, taking into account their vertical location within the canopy. For example, conventional footprint models that represent the canopy in a single-layer or 'big leaf' approach may be adequate to predict the footprint of daytime $\mathrm{CO}_{2}$ flux measurements, dominated by photosynthesis of the leaves, while they are likely to under-estimate the size of the footprint of night-time respiration which is dominated by soil emissions (Vesala et al., 2008).

Finally, there has been much interest recently in establishing source and sinks of heat and trace gases in plant canopies: these can provide valuable information on the plant compartments and biological processes determining the net exchange with plant canopies. The understanding of the in-canopy transport mechanisms is central to this analysis, which needs to establish relationships between concentration profiles and the vertical distribution of sources and sinks in the canopy. The size of the mean eddy motions in plant canopies is of the same order of magnitude as the canopy height $\left(h_{c}\right)$ and therefore large compared with the spacing of the sources and sinks of interest (Raupach et al., 1996). As a result, each layer within the canopy is not only in contact with the adjacent layers (as assumed in conventional $K$-theory), but also communicates with other layers further away. Source/concentration relationships which take these non-localized effects into account have been derived using Lagrangian stochastic particle models (e.g., Baldochi, 1992; Rodean, 1996), non-local higher-order closure schemes in Eulerian models (e.g., Katul et al., 2001), or using analytical approximations of Lagrangian concepts. The latter approach includes the Localized-Near-Field (LNF) theory of Raupach (1989a, b) and the Lagrangian solution of Warland and Thurtell (2000). In particular, LNF theory has been applied to derive source/sink distributions of sensible and latent heat, carbon dioxide $\left(\mathrm{CO}_{2}\right)$, ammonia $\left(\mathrm{NH}_{3}\right)$, methane $\left(\mathrm{CH}_{4}\right)$ and volatile organic compounds (VOCs) (Denmead and Raupach, 1993; Denmead, 1995; Denmead et al., 2000; Harper et al., 2000; Katul et al., 1997; Leuning, 2000; Leuning et al., 2000; Nemitz et al., 2000a; Karl et al. 2004). The application of this and related techniques requires an accurate knowledge of the in-canopy turbulence profiles, represented by the standard deviation of the vertical wind component $\left(\sigma_{w}\right)$ and the Lagrangian time-scale $\left(\tau_{L}\right)$, normalized by the friction velocity above the canopy $\left(u_{*}\right)$. Alternatively, the dissipation rate of turbulent kinetic energy $(\varepsilon)$ is used instead of $\tau_{L}$, since it may be argued that $\tau_{L}$ has no clear meaning when turbulence is inhomogeneous or non-Gaussian (Sawford, 1985).

One particular aim of this kind of analysis is to distinguish between emissions from the soil or ground layer and the vegetation, or to quantify in-canopy cycling processes and the fraction of the soil emission that is recaptured within the overlying canopy. For example, Nemitz et al. (2000a) and Harper et al. (2000) used LNF theory to quantify the ground emissions of $\mathrm{NH}_{3}$, originating from decomposing leaf litter and fertilizers, respectively. Leuning et al. (2000) derived emission fluxes of $\mathrm{CO}_{2}$ and $\mathrm{CH}_{4}$ on the water surface underlying a rice paddy, while Karl et al. (2004) applied LNF analysis to estimate the contribution of the understorey to net VOC emissions in a tropical forest. The magnitude of these ground level emissions is highly sensitive to the parameterization of the turbulence close to the ground, in the so-called unresolved basal layer (UBL) (Wilson and Flesh, 1993). Nemitz et al. (2000a) demonstrated, that, using the range of feasible parameterizations of $\sigma_{w}$, the ground-level emission could be quantified only within a factor of 4 . Additional uncertainty is introduced by a lack of understanding of the behaviour of $\tau_{L}$ and $\varepsilon$ near the ground, which are experimentally difficult to measure. While the parameterisation near the ground is important for deriving the ground level emissions by inverse modelling accurately, estimates of the net flux above the canopy and forward modelling approaches are less sensitive to the choice of this parameterisation (Nemitz et al., 2000a; Wohlfahrt, 2004).

So far, the in-canopy study of turbulence, pollutant cycling, chemistry and source-sink analyses has generally focussed on taller canopies such as forests and crops where profiles of turbulence, temperature and concentrations are easier to measure (Gardiner, 1994; Launiainen et al., 2007; Shaw et al., 1989, 1995; Wilson et al., 1982). Few studies (e.g., Aylor et al., 1993), however, report turbulence measurements within crops and a grass canopy. It is also generally assumed, that forests provide much more potential for in-canopy chemical interactions than short vegetation canopies. However, because short canopies such as grasslands or moss layers can be very dense, the residence time of tracers emitted from the soil can, nevertheless, be very long. Grasslands represent the most abundant single land cover class in Europe and are subject to a range of ground-level emissions such as soil respiration of $\mathrm{CO}_{2}$, soil emissions of $\mathrm{N}_{2} \mathrm{O}$ and $\mathrm{NO}$, and $\mathrm{NH}_{3}$ emissions from fertilizer and decaying leaf material.

As a further limitation, current representations of incanopy transport mechanisms, including standard LNF theory, do not account for the influence of atmospheric stability above and within plant canopies. As a result, standard LNF 
tends to overestimate night-time emissions compared with micrometeorological measurements by gradient or eddycorrelation (EC) technique (Leuning et al., 2000; Nemitz et al., 2000a). Leuning (2000) introduced a simple dependence of $\tau_{L}$ and $\sigma_{w}$ on the stability above the canopy which resulted in significantly better agreement between LNF and EC for fluxes of latent heat and $\mathrm{CO}_{2}$. However, it is clear that incanopy stability will also have an effect on the turbulence within the canopy. In the extreme case, during calm nights free convection must be expected to be the main transport mechanism in the bottom of dense canopies, and $\sigma_{w}$ is likely to be more closely linked to the free convective velocity scale $\left(w_{*}\right)$ than to $u_{*}$ (Nemitz et al., 2000a).

Furthermore, many relationships between profiles of concentrations and source/sink distributions are derived assuming turbulence within canopies to be Gaussian. The limitations of this assumption have been demonstrated for forests (Gardiner, 1994, 1995), especially under non-neutral conditions (Leclerc et al., 1991), while the limited measurements in short canopies have shown non-Gaussian turbulence (e.g. Aylor et al., 1993).

In this paper we present measurements of turbulence and radon transport within and above a grassland canopy, which were made in the framework of a major international field experiment within the EU project GRAMINAE ("GRassland AMmonia INteractions Across Europe", Sutton et al., 2009a). These measurements are used to investigate (i) turbulence parameters within grassland canopies, with particular emphasis on the UBL, (ii) intermittencies and Gaussianity of the turbulence, (iii) stability effects on $\sigma_{w}$, and (iv) the general importance of non-diffusive transport mechanisms in grassland canopies. The results are used to investigate whether in-canopy profiles of atmospheric ammonia $\left(\mathrm{NH}_{3}\right)$ are consistent with an $\mathrm{NH}_{3}$ source from senescent plant material on the ground surface.

\section{Methods and theory}

\subsection{Field site description}

Measurements took place from 21 May to 15 June 2000 at a 4-year old grassland at the German Federal Agricultural Research Institute (FAL), Braunschweig, Germany. The canopy was dominated by Lolium perenne, Phleum pratense and Festuca pratensis (Mattsson et al., 2009a) and its height $\left(h_{c}\right)$ increased from 0.65 on 20 May to $0.75 \mathrm{~m}$ on 29 May 2000 when it was cut. A cross section of the canopy and the leaf area density (LAD) profile is illustrated in Fig. 1. After the cut, some of the instrumentation was moved to the centre of a small plot of $20 \mathrm{~m} \times 20 \mathrm{~m}$ which was left uncut and continued to grow to a height of $0.85 \mathrm{~m}$, while the main field re-grew from $0.05 \mathrm{~m}$ to $0.35 \mathrm{~m}$ by 15 June. A summary of the overall experiment and the synoptic meteorology has been provided by Sutton et al. (2009a), the micrometeorological mea-

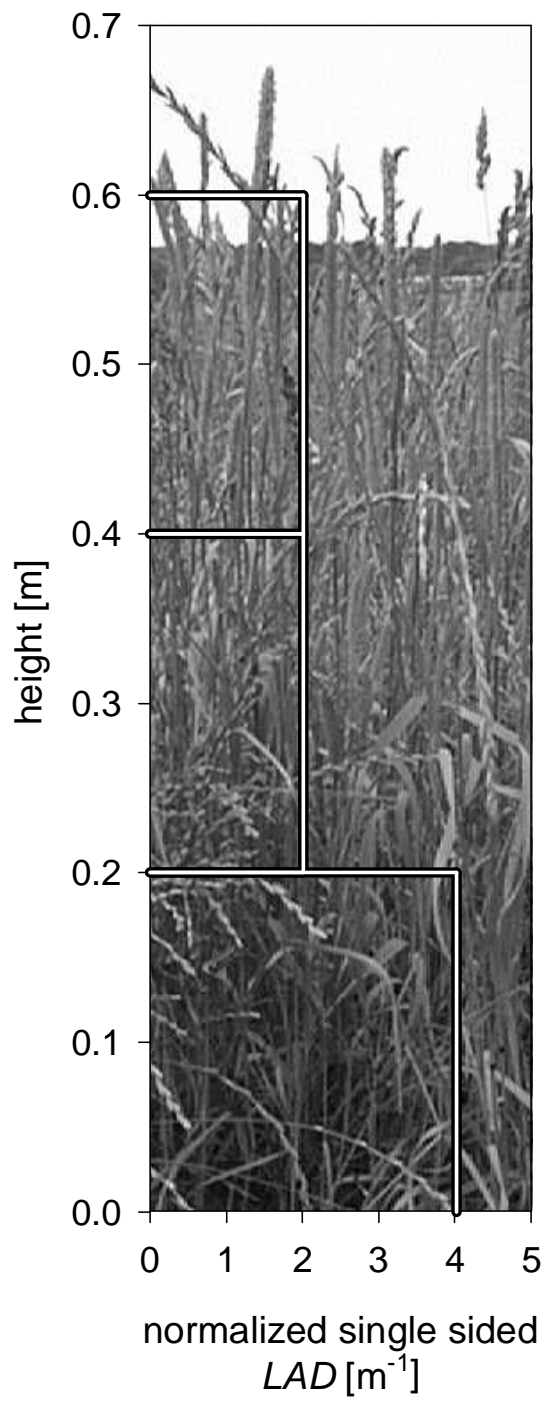

Fig. 1. Leaf area density profile and cross section of the tall grass canopy during the Braunschweig experiment (20 May 2000).

surements above the canopy have been described by Nemitz et al. (2009), while a more detailed description of the plant composition has been provided by Mattsson et al. (2009a).

\subsection{Turbulence measurements}

Turbulence parameters within the canopy were measured with a miniature ultrasonic anemometer, with a path-length of $5 \mathrm{~cm}$ (Model WA-590; Kaijo Corporation, Tokyo, Japan) and a sampling frequency of $20 \mathrm{~Hz}$. The height of this anemometer was varied over the height range $(z)$ of 0.05 to $1.2 \mathrm{~m}$, relating to a fractional height $\left(z / h_{c}\right)$ of 0.0625 to 1.5 , while care was taken that (a) grass blades did not obstruct the ultrasonic pathways and (b) the canopy was impacted as little as possible. The WA-590 was logged by a PC, together with a standard research anemometers (Solent 
Research R1012, Gill Instruments, Lymington, UK), operating at $20.83 \mathrm{~Hz}$, measuring the turbulence above the canopy, at a fixed height $\left(z_{m}\right)$ of $2.1 \mathrm{~m}$ (Nemitz et al., 2009). A data acquisition programme, written in LabView 5.0 (National Instruments) recorded the raw data and performed initial calculations of the main turbulent statistics and micrometeorological parameters. To obtain a more robust estimate of the turbulence parameters above the canopy, these were averaged over a total of 8 ultrasonic anemometers deployed during the experiment (Nemitz et al., 2009).

The data from the WA-590 were re-processed, using analysis routines also developed in LabView 5.0, which calculated micrometeorological parameters, turbulence statistics, spectral and co-spectral density functions, combined frequency distributions, quadrant-hole analysis and intermittency parameters for each 15-min interval.

A three-dimensional hotwire anemometer system was constructed by mounting three single-wire anemometers (TSI 8465, Minnessota, USA) perpendicular to each other so that each wire measured two components of the instantaneous wind speed. The range of wind speed range was set to 0 $2.5 \mathrm{~m} \mathrm{~s}^{-1}$, and data were recorded at a sampling frequency of $5 \mathrm{~Hz}$. In practice, power spectral analysis showed aliasing for frequencies larger than $2 \mathrm{~Hz}$. A thin thermocouple $(25.4 \mu \mathrm{m})$ was mounted next to the wires to measure the temperature fluctuations, but at a distance $(5 \mathrm{~cm})$ sufficient to avoid any direct influence of the heated wires on the temperature measurements. The velocity $\left(q_{i}\right)$ measured by each wire is a function of the wind component normal to that wire $u_{n}$ and the component parallel to the wire $\left(u_{p}\right)$ (Buresti and Talamelli, 1992): $q_{i}^{2}=u_{n}^{2}+\beta u_{p}^{2}$, where the constant $\beta$ was assumed to be the same for the three wires. With this hypothesis, the sum of the three hotwires averaged velocities $\left(\sum \overline{q_{i}^{2}}\right)$, which is equal to the turbulent kinetic energy $e_{h w}^{2}$ can be related to the Eulerian turbulent kinetic energy $\left(e^{2}\right)$ through $e_{h w}^{2}=(2+\beta) e^{2}$ In order to determine the constant $\beta$, the three hotwires were placed next to an ultrasonic anemometer in the field for a period of more than $24 \mathrm{~h}$. The value of $\beta$ was then determined by a linear regression between $e_{h w}^{2}$ and $e^{2}$ over 1473 periods of $1 \mathrm{~min}$, which were filtered for averaged velocity measured on the hotwires smaller than $2.5 \mathrm{~m} \mathrm{~s}^{-1}$. A value of $\beta=0.31$ was found over a range of $e^{2}$ from 0 to $20 \mathrm{~m}^{2} \mathrm{~s}^{-2}\left(R^{2}=0.95\right)$.

\subsection{Measurements of profiles of temperature and am- monia}

The temperature profile in and above the canopy was continuously measured at two locations, using fine E-type thermocouples $\left(0.002^{\prime}\right.$ diameter), which were logged by dataloggers (Model 21x, Campbell Scientific Ltd, Lymington, UK). One set (operated by CEH) measured temperature at the heights $0.02,0.05,0.15,0.25,0.35,0.45,0.55$ and $0.65 \mathrm{~m}$ above the ground, while a second set (operated by INRA) recorded the temperature at $0.02,0.10,0.20,0.40,0.70$ and $1.0 \mathrm{~m}$. Af- ter the cut of the main field the $\mathrm{CEH}$ temperature profile and the WA-590 were moved to a small plot of tall grass, while the INRA temperature profile and the hotwire anemometer continued to measure above the short, cut grassland.

To study the sources and sinks of ammonia in the grassland canopy, an attempt was made to measure in-canopy profiles with low flow-rate continuous wet-chemistry $\mathrm{NH}_{3}$ sensors (with the detectors of the REA systems of ECN and FAL$\mathrm{CH}$, cf. Hensen et al., 2008a) over a 6-day period at a total of five measurement points: 0.15 (ECN), 0.15 (FAL-CH), 0.25 (FAL-CH), 0.35 (ECN) and $0.45 \mathrm{~m}$ (FAL-CH). The duplication at $z=0.15 \mathrm{~m}$ was meant to act as a reference between the two independent system. Unfortunately, the channel $0.15 \mathrm{~m}$ (FAL-CH) malfunctioned and the reference was lost. In addition, as demonstrated below, much of the vertical changes in $\mathrm{NH}_{3}$ concentration were found to occur below $0.15 \mathrm{~m}$. Therefore these continuous measurements remained inconclusive.

However, individual more highly vertical resolved vertical profiles of $\mathrm{NH}_{3}$ were measured using a single fast $\mathrm{NH}_{3}$ sensor (Hensen et al., 2008b). These provided relative measurements which were scaled to match the mean estimates of above-canopy $\mathrm{NH}_{3}$ concentrations (Milford et al., 2008). The fast-response $\mathrm{NH}_{3}$ profile measurements were made after the main field was cut on 29 May, in a smaller plot set aside for continued measurements of bio-assays and incanopy behaviour, while the main micrometeorological measurements continued on the main field.

\subsection{Similarity theory}

In the neutral boundary layer $\sigma_{w}$ scales with the friction velocity $\left(u_{*}\right)$

$u *=\sqrt{-\overline{u^{\prime} w^{\prime}}}$,

while $\sigma_{u}$ and $\sigma_{v}$ depend on larger scale structures by convection cells and topography (Högström et al., 1989; Raupach et al., 1991, 1996). However, above the surface roughness layer, the standard deviations of all three wind components $\left(\sigma_{u}, \sigma_{v}, \sigma_{w}\right)$ are often normalised by $u_{*}$ (e.g., Panofsky and Dutton, 1983; Brunet and Collineau, 1994): $\sigma_{u}=2.39$ [1.8-3.4] $u_{*}, \sigma_{v}=1.92$ [1.5-2.9] $u_{*}, \sigma_{w}=1.25$ [1.13-1.35] $u_{*}$. Therefore, the total turbulent kinetic energy $\left(e^{2}\right)$ is given by $e^{2}=\sigma_{u}^{2}+\sigma_{v}^{2}+\sigma_{w}^{2}=11.0[6.8-21.8] u_{*}^{2}$.

Leuning (2000) suggested a variation of $\sigma_{w}$ with atmospheric stability above the canopy:

$\sigma_{w}(\varsigma)=\frac{\phi_{M}(\varsigma)}{1.25} \sigma_{w, n}(\varsigma)$

where $\phi_{M}(\zeta)$ is the stability correction function for momentum (e.g., Kaimal and Finnigan, 1994), and $\sigma_{w, n}$ is the value of $\sigma_{w}$ under neutral conditions. The dimensionless stability parameter $(\zeta)$ is defined as

$\zeta= \begin{cases}h_{c} / L & z<z_{\text {ruf }} \\ (z-d) / L & z>z_{\text {ruf }}\end{cases}$ 
where $d$ is the zero plane displacement height (typically $d=0.75 h_{c}$ ), $L$ is the Obukhov stability length (e.g. Garratt, 1996)

$L=-\frac{u_{*}^{3}}{\kappa(g / T)\left(H / \rho_{a} c_{p}\right)}$,

and $z_{\text {ruf }}$ is the height of the boundary between the roughness sublayer and the inertial sublayer. Alternatively, below $z_{\text {ruf }}, \zeta$ may be defined as $\zeta=\left(h_{c}-d\right) / L$ (Kaimal and Finnigan, 1994), with little difference on the stability correction of Eq. (4) (Leuning, 2000). This stability correction is a function of the atmospheric stability above the canopy, which is derived from $H$ and $u_{*}$ (Eq. 2), both of which loose their physical meaning within the canopy. By contrast, a heightdependent local stability parameter $\left(\zeta^{\prime}(z)\right)$ may be defined either from the temperature profile at the individual height.

In free convection, turbulent parameters scale with the convective velocity scale $\left(w_{*}\right)$ rather than with $u_{*}$ (e.g. Stull, 1988):

$w_{*}=\left(g \frac{\overline{w^{\prime} T^{\prime}}}{T} z_{i}\right)^{1 / 3}$

where $g$ is the acceleration due to gravity and $z_{i}$ is the depth of the inversion layer. The definition of $w_{*}$ relies on the heat flux $\left(H=\rho_{a} c_{p} \overline{w^{\prime} T^{\prime}}\right)$ to be constant with height, just like $u_{*}$ assumes the shear stress to be constant with height. This is obviously not fulfilled within plant canopies with sources and sinks of sensible heat caused by interception of incoming radiation and the inter-conversion of sensible and latent heat. Nevertheless, $w_{*}$ calculated from the ground heat flux at the surface $(G)$ should be representative for the very bottom of the canopy. In this study $G$ was derived as the sum of the soil heat flux measured at a depth of $0.1 \mathrm{~m}$ and the heat storage in the top $0.1 \mathrm{~m}$ soil layer, estimated from changes in soil temperature, and is taken as positive if directed upwards. Many studies have assumed $z_{i}$ to be the top of the canopy. By contrast, on most nights, the in-canopy temperature gradients measured at our grassland site showed a temperature minimum near $z_{i} / h_{c}=0.54$ (cf. Nemitz et al., 2009).

According to similarity theory, turbulent transport of gases is governed by the flux gradient relationship for heat $\left(K_{f}\right)$. Under homogeneous and Gaussian turbulence, this far field diffusivity is related to standard deviation of the vertical wind velocity $\left(\sigma_{w}\right)$ and the Lagrangian time scale $\left(\tau_{L}\right)$ (e.g., Raupach, 1989a):

$K_{f}(z)=\sigma_{w}(z)^{2} \tau_{L}(z)$

\subsection{Two-parametric probability distributions and quadrant hole analysis}

The analysis of the two-parameteric probability distributions of $u^{\prime}(t) . w^{\prime}(t)$ provides information on the transport mechanism of momentum within and above the canopy. Conventionally, the four quadrants $(i)$ of the $u^{\prime} w^{\prime}$ plane are referred to as outward interaction $\left(i=1 ; u^{\prime}>0 ; w^{\prime}>0\right)$, ejection $\left(i=2 ; u^{\prime}<0 ; w^{\prime}>0\right)$, inward interaction $\left(i=3 ; u^{\prime}<0 ; w^{\prime}<0\right)$ and sweeps $\left(i=4 ; u^{\prime}>0 ; w^{\prime}<0\right)$. Quadrant-hole $(\mathrm{Q}-\mathrm{H})$ analysis is a commonly used technique for a more quantitative analysis of the contribution of extreme events (gusts) to the overall transport of momentum, heat or entrained properties. Based on the two-parametric probability distribution, a stress fraction may be defined according to (e.g., Lee and Black, 1993):

$$
\begin{aligned}
S_{i, H} & =\frac{1}{\left|u^{\prime} w^{\prime}\right|} \frac{1}{T} \int_{0}^{T} u^{\prime}(t) w^{\prime}(t) I_{i, H} \mathrm{~d} t \\
t_{i, H} & =\frac{1}{T} \int_{0}^{T} I_{i, H} \mathrm{~d} t
\end{aligned}
$$

where $T$ is the averaging period ( $30 \mathrm{~min})$. Here, $I_{i, H}$ equals one if two conditions are fulfilled: (i) $u^{\prime}(t) w^{\prime}(t)$ lies in the $i$-th quadrant and (ii) $\left|u^{\prime}(t) w^{\prime}(t)\right|>H_{u w}\left|u^{\prime} w^{\prime}\right|$, where $H_{u w}$ is the hole size. $I_{i, H}$ is zero otherwise. $S_{i, H}$ is therefore a measure of the fraction of momentum carried by extreme events in quadrant $i$, which exceed the average momentum transfer by at least a multiple of $H_{u w}$. Based on this Q-H analysis, the following additional intermittency parameters may be defined: the half hole size $\left(H_{1 / 2}\right)$ is the hole size above which half of the momentum transfer occurs, i.e.

$$
\left|\sum_{i=1}^{4} S_{i, H_{1 / 2}}\right|=0.5 \text {, }
$$

Similarly, $t_{1 / 2}$ is defined as the fraction of time during which half of the momentum transfer occurs through the most extreme events. For example, a $t_{1 / 2}$ of 0.08 indicates that half of the momentum is transferred in extreme events which occupy $8 \%$ of the time. In addition, the exuberance is defined as the ratio of the interaction components divided by the sum of sweeps and ejections, i.e. $\left(S_{1,0}+S_{3,0}\right) /\left(S_{2,0}+S_{4,0}\right)$ (Shaw et al., 1983).

\subsection{The radon tracer technique}

For physical reasons, the acoustic anemometer could not be used to gain information of turbulence below a height of $0.05 \mathrm{~m}$. Instead, transport times in the lowest layers of the canopy (up to $0.15 \mathrm{~m}$ ) were derived using the ${ }^{220} \mathrm{Rn}$ tracer technique (Lehmann et al., 1999, 2002). This technique utilizes two radon isotopes that are continuously released from soils: the short-lived ${ }^{220} \mathrm{Rn}\left(T_{1 / 2}=55.6 \mathrm{~s}\right)$ is a decay product of ${ }^{224} \mathrm{Ra}$ in the natural ${ }^{232} \mathrm{Th}$ alpha-decay series, while the long-lived ${ }^{222} \mathrm{Rn}\left(T_{1 / 2}=3.82\right.$ days $)$ is a decay product of ${ }^{226} \mathrm{Ra}$ in the natural ${ }^{238} \mathrm{U}$ alpha-decay series. The activities of both isotopes were monitored at three heights using a gradient system consisting of two commercial total Rn analyzers (ALPHAGUARD Model PQ2000 PRO, Genitron Instruments, Frankfurt, Germany; Lehman et al., 1999). Activities of the two isotopes were distinguished by measurement of the combined activity before and after passing the 
sample air through a delay volume with a residence time of $340 \mathrm{~s}$, during which $98 \%$ of the ${ }^{220} \mathrm{Rn}$ decays (Lehmann et al., 1999). At Braunschweig, the Rn monitors were operated for a 5-day period before the cut (21-26 May 2000), with measurements at $0.02,0.08$ and $0.15 \mathrm{~m}$ within the $0.7-0.8 \mathrm{~m}$ tall canopy. After the cut, measurements continued at these heights, now partially above the canopy (1-15 June 2000). The three heights were sampled sequentially, switching between lines every $20 \mathrm{~min}$, thus obtaining a dataset with one activity concentration $\left(\mathrm{Bq} \mathrm{m}^{-3}\right)$ per hour for each height and both $\mathrm{Rn}$ isotopes.

The profiles of ${ }^{220} \mathrm{Rn}$ allow the transport times within the lowest part of the canopy to be determined and estimates of the eddy diffusivity $\left(K_{f}(z)\right)$ to be derived. In two alternative approaches, $K_{f}(z)$ is either assumed to be constant over the range of measurement heights, or thought to increase linearly in $z$, i.e.

$K_{f}(z)=K_{z} \times z+K_{0}$

with the molecular diffusivity $\left(K_{0}=1.2 \times 10^{-5} \mathrm{~m}^{-2} \mathrm{~s}^{-1}\right.$; Hirst and Harrison, 1939) providing the boundary value at the ground surface, and $K_{z}$ being the slope. The numerical procedure of deriving $K_{z}$ from the activity profiles has been presented elsewhere (Lehmann et al., 1999). In brief, the technique relies on solving the differential equation

$\partial_{t} n=\partial_{z}\left|K-f(z) \partial_{z} n\right|-\lambda n$

with the boundary conditions

$-\left.K_{f} \partial_{z} n\right|_{z=0}=j_{0} ;\left.\quad n\right|_{z=\infty}=0$,

where $t$ is the time; $z$ is the height above the surface; $n$ is the concentration of ${ }^{220} \mathrm{Rn}$ - atoms per volume; $K_{f}$ is the diffusion coefficient, $j_{0}$ is the flux of ${ }^{220} \mathrm{Rn}$ through the surface, $\partial$ is the radioactive decay constant of ${ }^{220} \mathrm{Rn}$. As a working hypothesis the diffusion coefficient of ${ }^{220} \mathrm{Rn}$ in air is a linear function in $z$ according to Eq. (10). The measured activity concentration $A$ (in $\mathrm{Bq} \mathrm{m}^{-3}$ ) is calculated from the product $A=n \times \lambda$. It can be shown that under stationary conditions an analytical solution for Eqs. (11) and (12) for the vertical activity profile exists, involving modified Bessel functions of the second kind of order 0 and 1 (Ikebe and Shimo, 1971). Two activities $A\left(z_{1}\right)$ and $A\left(z_{2}\right)$ measured at different heights unambiguously determine the full profile and the necessary Rn-flux $j_{0}$ from the soil surface. Individual activity measurements in our experimental set-up have a considerable statistical error due to the low count rates (on the order of 10-30 counts only in a 10 min counting interval). To this may be added uncertainties associated with sequential sampling under conditions of changing air concentrations. Therefore, evaluating time series of activity ratios e.g. $A(0.02 \mathrm{~m}) / A(0.08 \mathrm{~m})$ yields parameters $\left(K_{z}, j_{0}\right)$ with temporal variations that are partly due to the statistical error of the activity data. It is to be expected, however, that the ${ }^{220} \mathrm{Rn}$ flux from the surface remains essentially constant, in partic- ular over short time scales when the soil conditions are constant. We therefore selected the following data evaluation procedure:

a) The ${ }^{220} \mathrm{Rn}$-flux from the surface was set to be constant. A numerical value of $j_{0}=0.4 \mathrm{~Bq} \mathrm{~m}^{-2} \mathrm{~s}^{-1}$ appears to give a best fit over the full measuring period of almost 4 weeks.

b) Using this flux and the measured ${ }^{220} \mathrm{Rn}$ - activity $A(0.02 \mathrm{~m})$ at the lower level, a first value for $K_{z}$ can unambiguously be calculated.

c) Step b) was repeated with the second level using $A(0.08 \mathrm{~m})$; however, at this level one has to verify that from two possible solutions the correct $K_{z}$ is selected.

d) The two resulting numerical values for $K_{z}$ were averaged using at relative weight of 2:1 for the lower and the upper level to take into account the approximate ratio of the relative errors of the two measurements.

By contrast, as an inert tracer which is released from the ground at a nearly constant rate, the profiles of ${ }^{222} \mathrm{Rn}$ are ideal for the assessment and validation of parameterizations of turbulence parameters close to the ground.

\section{Results}

\subsection{Turbulence statistics}

Figure 2 summarizes the normalized profiles of $\sigma_{u}, \sigma_{v}, \sigma_{w}$, $e^{2}$ and wind speed $(u)$, averaged over all windy conditions $\left(u_{*}>0.2 \mathrm{~m} \mathrm{~s}^{-1}\right)$, during which turbulent diffusion is likely to dominate over convectively driven transport processes. Also shown in this figure are sigmoidal fits of the form:

$$
y(x)=y_{0}+\frac{a}{1+\exp \left(-\frac{x-x_{0}}{b}\right)}
$$

where $x$ is the dimensionless height $\left(z / h_{c}\right)$; the coefficients are summarized in Table 1.

The measurements of $\sigma_{w} / u_{*}$ in Fig. $2 \mathrm{~d}$ are compared with parameterizations suggested by Raupach (1989b) and Leuning et al. (2000) and computed from the measured leaf area density profile (Fig. 1), using the model by Massman and Weil (1999). Not all parameters for this model are well defined for this study. Following their original notation, we use above-canopy values of $\gamma_{1}=\sigma_{u} / u_{*}=2.4, \gamma_{2}=\sigma_{v} / u_{*}=1.9$ and $\gamma_{3}=\sigma_{w} / u_{*}=1.25$, together with their standard parameters to describe the vertical in-canopy wind speed profile $\left(c_{1}=0.32, c_{2}=0.264, c_{3}=15.1\right)$. The free model parameter defining the length scale of the turbulence was set to $\alpha=0.05$, a little smaller than Massman and Weil (1999) derive for a wheat canopy, and $A_{2}=0.6$. 
Table 1. Coefficients of the sigmoidal approximations of Eq. (2), presented in Fig. 2.

\begin{tabular}{lccccccc}
\hline Parameter $(y)$ & $y_{0}$ & $x_{0}$ & $a$ & $b$ & $y(0)$ & $y(\infty)$ & $y(\infty)$, literature \\
\hline$u / u_{*}$ & 0.0617 & 0.824 & 4.68 & 0.103 & 0.0633 & N/A & N/A \\
$\sigma_{u} / u_{*}$ & 0.264 & 0.702 & 2.03 & 0.114 & 0.268 & 2.29 & 2.39 \\
$\sigma_{v} / u_{*}$ & 0.285 & 0.755 & 1.89 & 0.116 & 0.288 & 2.18 & 1.92 \\
$\sigma_{w} / u_{*}$ & 0.188 & 0.689 & 1.12 & 0.122 & 0.192 & 1.31 & 1.25 \\
$e^{2} / u_{*}^{2}$ & 0.235 & 0.811 & 12.01 & 0.101 & 0.239 & 12.24 & 10.96 \\
\hline
\end{tabular}

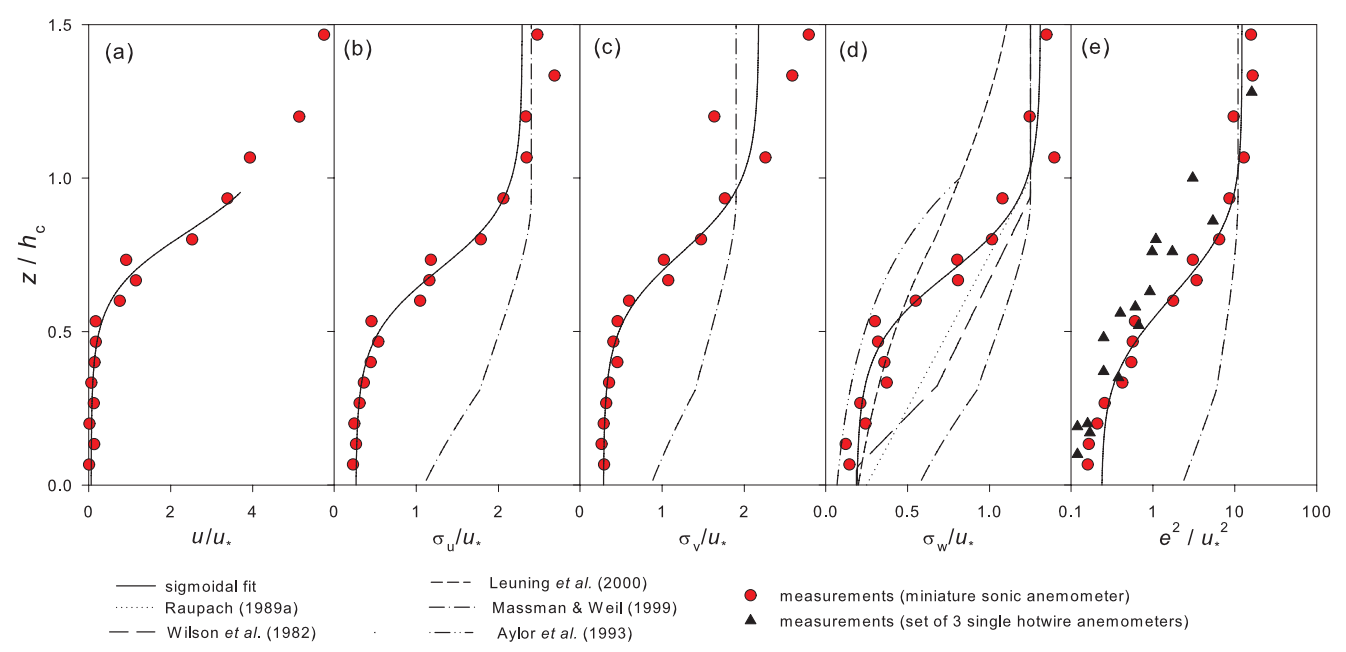

Fig. 2. Profiles of the standard deviations of the individual wind components normalized by $u_{*}$ measured above the canopy under windy conditions $\left(u_{*}>0.2 \mathrm{~m} \mathrm{~s}^{-1}\right)$, averaged over all stabilities. Circles indicate measurements with the miniature ultrasonic anemometer, while the triangles were derived with the hotwire anemometer.

In order to investigate the effect of above-canopy atmospheric stability on the within-canopy profile of $\sigma_{w} / u_{*}$, Fig. 3a shows the average profiles classified by $L$ into nearneutral, unstable and stable atmospheric conditions. Similarly, in Fig. 3b the profiles are classified according to incanopy stability, where the sign of $G$ is taken as a proxy. Using this bulk analysis, neither classification reveals a significant dependence of $\sigma_{w} / u_{*}$ on stability.

To investigate the effect of stability on $\sigma_{w} / u_{*}$ more systematically, Fig. 4 shows the values of $\sigma_{w}$, normalized by the value expected for neutral conditions $\left(\sigma_{w, n}\right)$ in relation to the stability parameter $\zeta$. Above the canopy, the measurements agree very closely with the parametrisation suggested by Kaimal and Finnigan (1994) for unstable conditions, while in stable conditions, the parametrisation of Merry and Panofsky (1976) provides the better fit. Inside the canopy there is an increased amount of scatter. For unstable conditions the measurements are still close to the above-canopy parametrisation, with the effect of stability possibly being more pronounced. For stable conditions, however, $\sigma_{w} / u_{*}$ appears to be reduced within the canopy compared with the neutral case, while above the canopy values are enhanced.

\subsection{Time-scales and coefficients of in-canopy transport derived from the Radon activity profiles}

Two-hour running means of raw $\mathrm{Rn}$ activity profiles for ${ }^{220} \mathrm{Rn}$ and ${ }^{222} \mathrm{Rn}$ are presented in Fig. 5. Before the cut, ${ }^{220} \mathrm{Rn}$-activities show a clear vertical pattern indicating that there are considerable kinetic constraints on transport between 2 and $15 \mathrm{~cm}$ (comparable to one half-life of this isotope of $56 \mathrm{~s}$ ), but even after the cut, concentrations at $2 \mathrm{~cm}$ greatly exceed the other concentrations, especially during night. After the cut, peak activities of ${ }^{220} \mathrm{Rn}$ after midnight are generally somewhat lower and daily patterns are more pronounced than before the cut, indicating that, during the day, air is removed from the lowest layers more efficiently than inside the tall grass canopy. After the cut, calm nights are characterised by high concentrations and pronounced vertical patterns for ${ }^{220} \mathrm{Rn}(3,5,9,10$ and 13 June). For the long-lived $\mathrm{Rn}$ isotope $\left({ }^{222} \mathrm{Rn}\right.$; half-life 3.8 days), clear gradients could only be observed before the grass was cut. Overall amplitudes for both $\mathrm{Rn}$ isotopes appear to be correlated; a period with low activities near ground for both nuclides (6-9 June), for example, indicates windy conditions. 


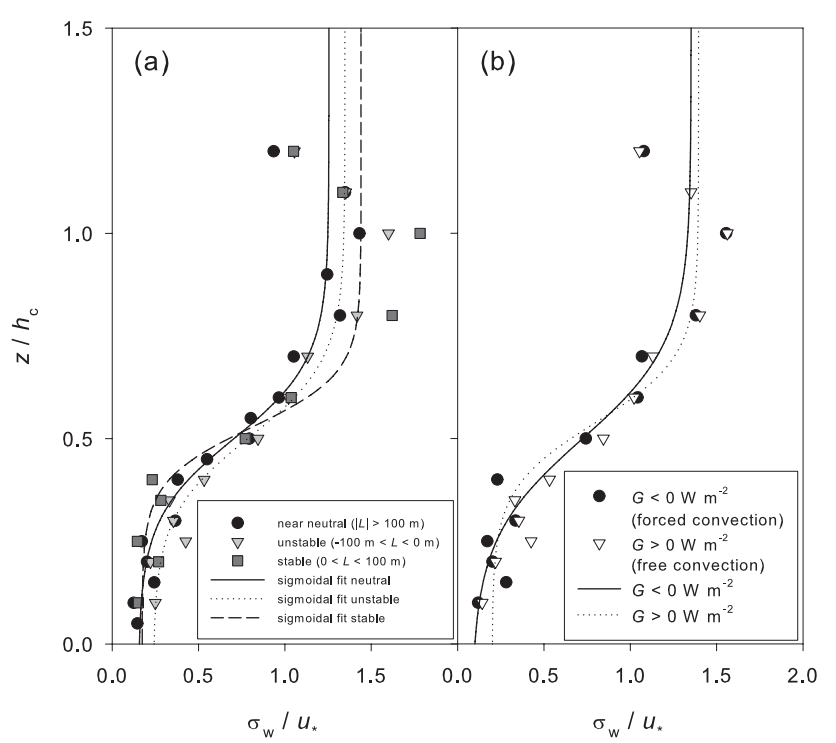

Fig. 3. In-canopy vertical profiles of $\sigma_{w} / u_{*}$ classified according to (a) Obukhov length $(L)$, reflecting above-canopy atmospheric stability and (b) ground heat flux $(G)$, driving in-canopy convection.

The result of the inversion is presented in Figs. 6 and 7, which shows the slope $K_{z}$ of the linear model (Eq. 1), and the diffusion coefficient $(K)$ at the three heights $(\mathrm{z}=2 \mathrm{~cm}, 8 \mathrm{~cm}$ and $15 \mathrm{~cm}$ ), respectively. The smallest values of $K$ (below $K=10^{-4} \mathrm{~m}^{2} \mathrm{~s}^{-1}$ ) were derived for the night of 23 to 24 May near the surface $(\mathrm{z}=0.02 \mathrm{~m})$ inside the grass canopy. After the grass was cut, several situations with slow vertical transport occurred during several nights.

The diffusive transport $\left(t_{d}\right)$ from the ground to the main measurement height may be estimated from the aerodynamic resistance $\left(R_{a}(z)\right)$, which can be identified by integration of the reciprocal $K_{f}(z)$ with height (e.g. Garland, 1977):

$$
\begin{aligned}
& t_{d}(z)=\frac{z}{R_{a}(z)}=z\left[\int_{0}^{z} K_{f}^{-1}\left(z^{\prime}\right) \mathrm{d} z^{\prime}\right]^{-1}= \\
& z\left[\int_{0}^{z} \frac{1}{K_{0}+K_{z} \times z^{\prime}} \mathrm{d} z^{\prime}\right]^{-1} .
\end{aligned}
$$

The values of $t_{d}$ calculated from the $K_{f}$ profiles derived from the $\mathrm{Rn}$ gradients are shown in Fig. 7. In the tall grass canopy values range from $40 \mathrm{~s}$ during the day to over $200 \mathrm{~s}$ during night, while above the short canopy values range from $10 \mathrm{~s}$ during most day-time conditions to almost $100 \mathrm{~s}$ during calm nights.

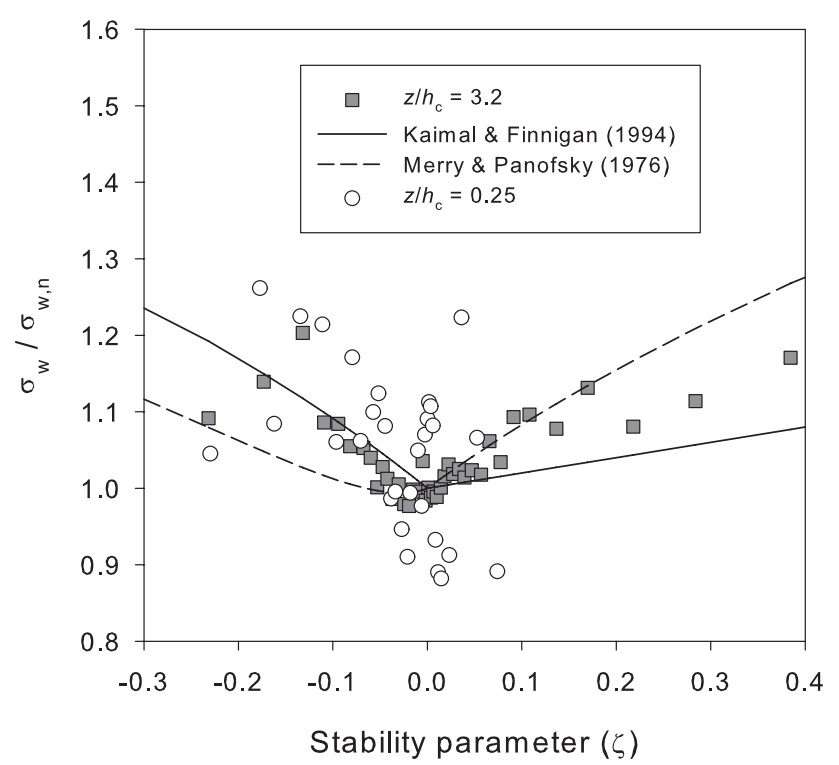

Fig. 4. Values of the ratio of measured standard deviation of the vertical wind component $\left(\sigma_{w}\right)$ to its value for neutral conditions $\left(\sigma_{w, n}\right)$ above (squares) and within the canopy (circles) as a function of the stability parameter $(\zeta)$ where $\zeta<$ w refers to unstable conditions and $\zeta>\mathrm{w}$ refers to stable conditions. The two lines represents parametrisations previously suggested to apply above the canopy.

\subsection{Gaussianity and intermittencies}

The two-parameteric probability functions of $u^{\prime}(t) \cdot w^{\prime}(t)$, presented in Fig. 8 for four different heights, illustrate the main characteristics of the momentum transfer at the different levels within and above the canopy. For this figure, periods with similar turbulence were selected (above-canopy $u_{*}$ ranging between 0.52 and $0.62 \mathrm{~m} \mathrm{~s}^{-1}$ ).

Averaged gradients of the most commonly used quantifiers of non-Gaussianity, i.e. skewness and kurtosis, are presented in Figs. 9 and 10, respectively. Skewness is a measure for the symmetry of a Gaussian distribution, where a positive value indicates an asymmetric tail towards larger values, while a negative value reflects a bias towards larger values. Similarly, a positive kurtosis (leptokurtosis) indicates that the peak of the distribution is narrower, with thicker tails than that of a Gaussian distribution, while negative kurtosis (platykurtosis) refers to a wider peak with thinner tails. We here use the convention that a Gaussian distribution has a kurtosis of 0 (rather than 3 as used in some other studies).

Figure 11 shows the stress function as a function of hole size and height for each of the interactions (quadrants). The vertical profiles of the different parameters for momentum transfer derived from this analysis are shown in Fig. 12, together with the ratio of sweeps and ejections.

Based on Figs. 8 to 12 the following characteristics of the turbulence can be summarized: 


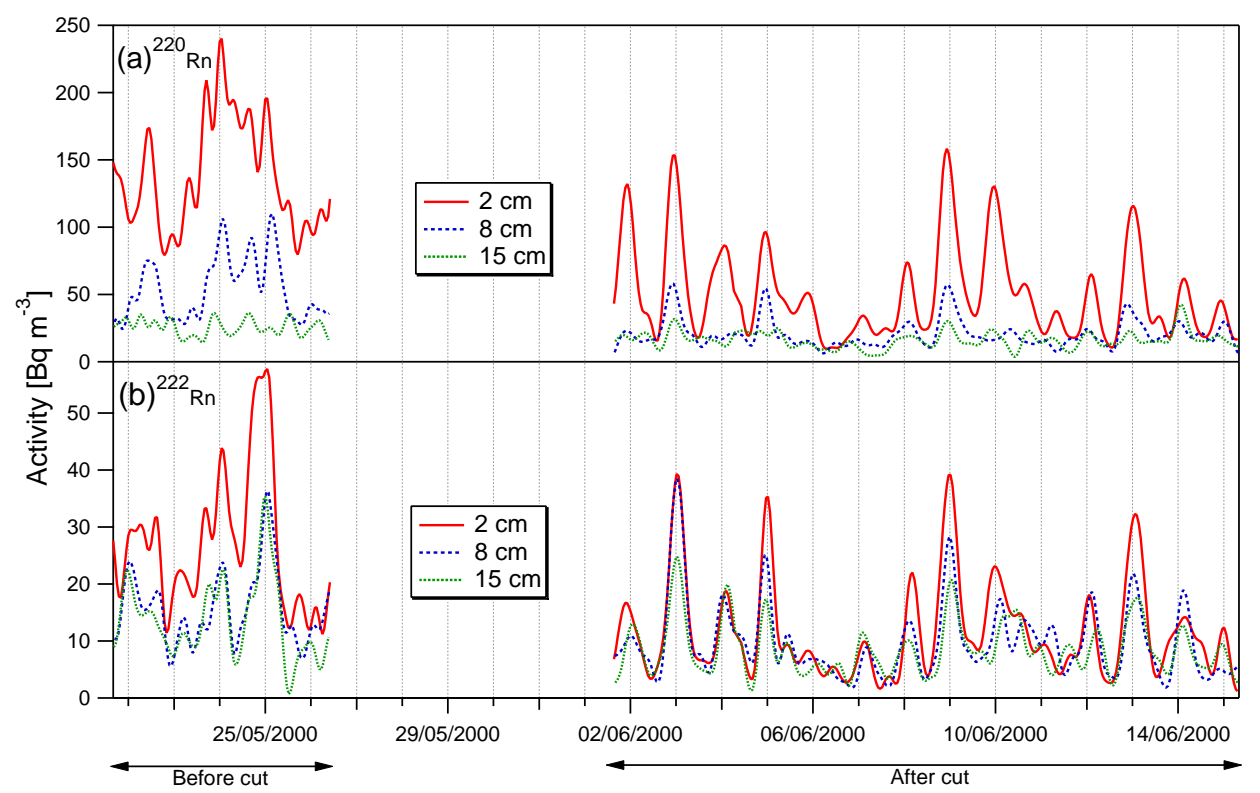

Fig. 5. Raw activity profiles of (a) the short-lived Radon-220 and (b) the long lived Radon-222 activities at three heights above the soil surface before and after the grass was cut (2-h running mean).

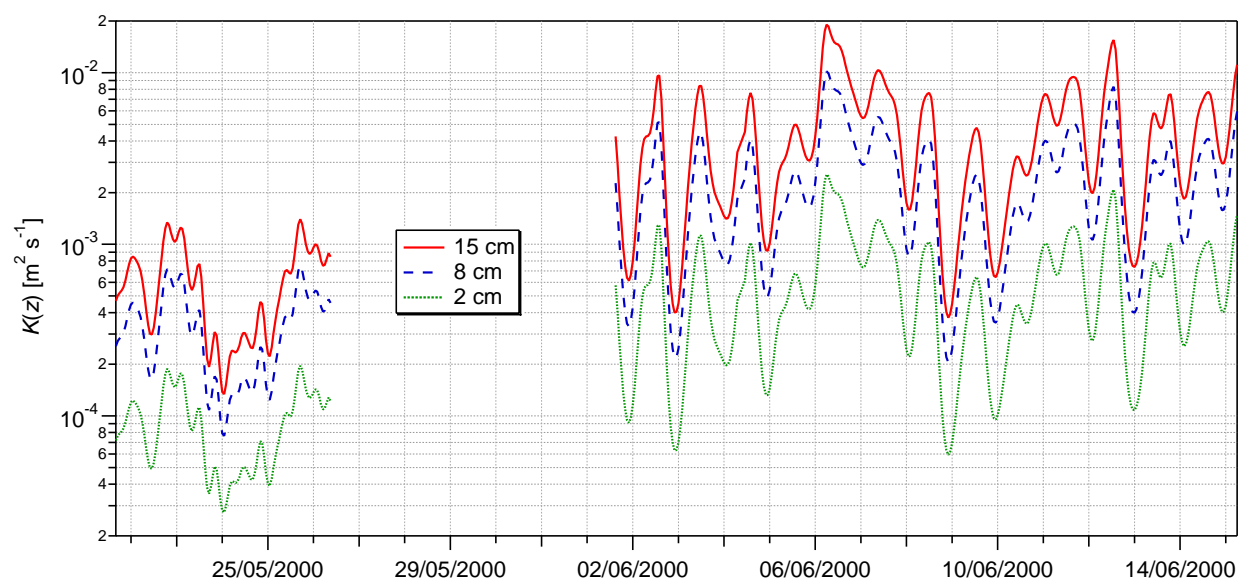

Fig. 6. Calculated diffusion coefficient $\left(K_{f}(z)\right)$ at three heights based on ${ }^{220} \mathrm{Rn}$-data and a constant surface flux $\left(j_{0}\right)$ of $0.4 \mathrm{~Bq} \mathrm{~m}^{-2} \mathrm{~s}^{-1}$.

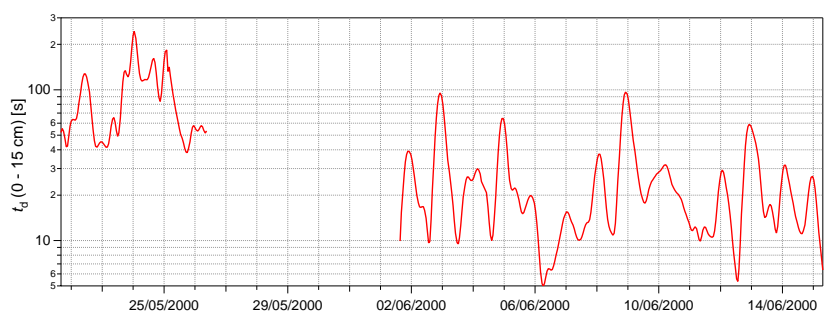

Fig. 7. Time of diffusive transport $\left(t_{d}\right)$ between the ground and the top sampling height $(15 \mathrm{~cm})$ derived from the Radon measurements. a) Above the canopy $\left(z / h_{c}=1.33\right.$; Fig. 8a) the distribution has the approximate shape of a Gram-Charlier distribution (e.g. Raupach et al., 1991), a near-Gaussian distribution which is slightly skewed towards positive $u^{\prime}$ and negative $w^{\prime}$.

b) In the top layer of the canopy $\left(z / h_{c}=0.93\right)$, the distribution becomes noticeably elongated with sweeps making an important contribution to the momentum transfer (Fig. 8b). Sweeps and ejections are the main transport mechanism (Fig. 11), with sweeps dominating over ejections (Fig. 12d) and $50 \%$ of the momentum is 

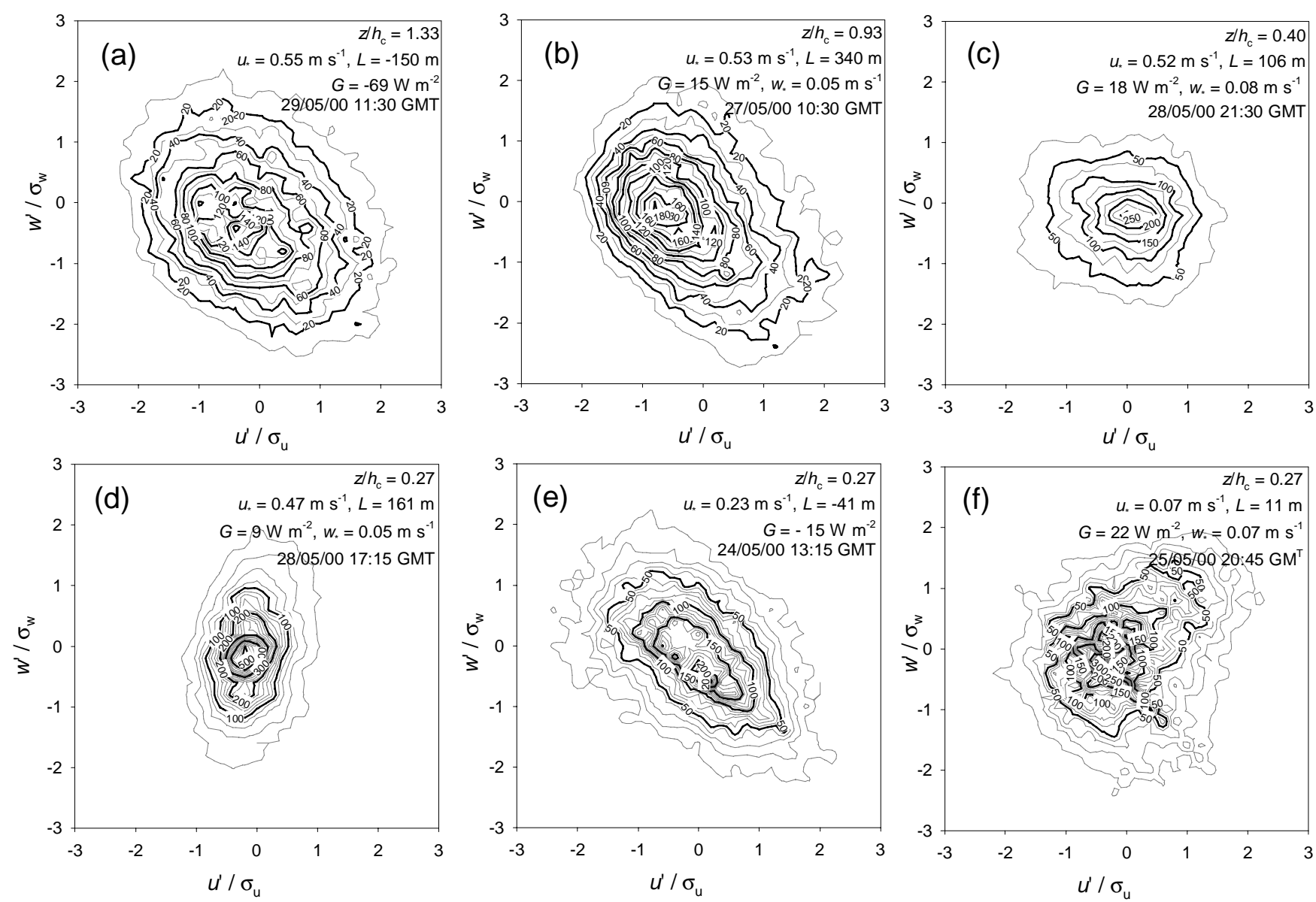

Fig. 8. Example two-parametric frequency distributions of $u^{\prime}(t) w^{\prime}(t)$ at three heights within and one above the grass canopy. The free convective velocity scale $\left(w_{*}\right)$ is only provided for conditions where $G$ is upwards (positive).

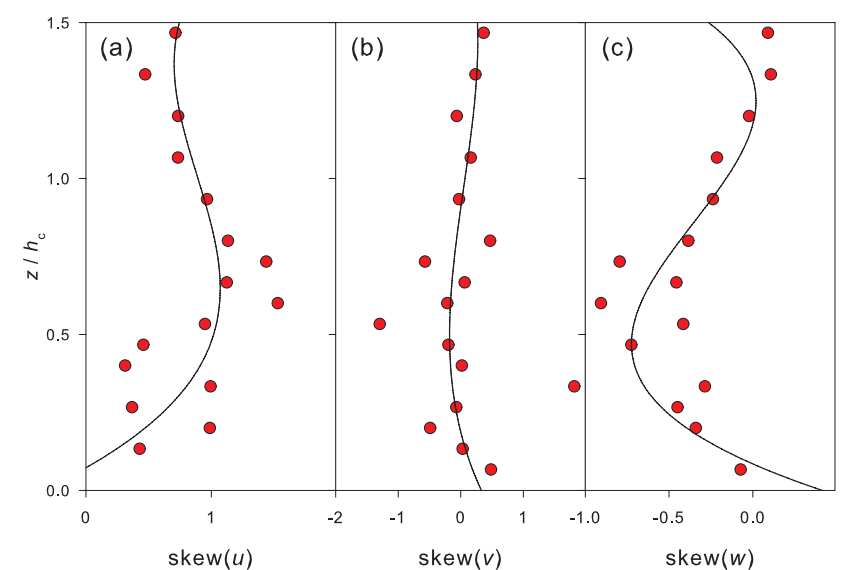

Fig. 9. Averaged profiles of the skewness of the individual wind components obtained with the miniature ultrasonic anemometer, together with 3rd order polynomial fits. A Gaussian distribution (unskewed would have a skewness of zero).

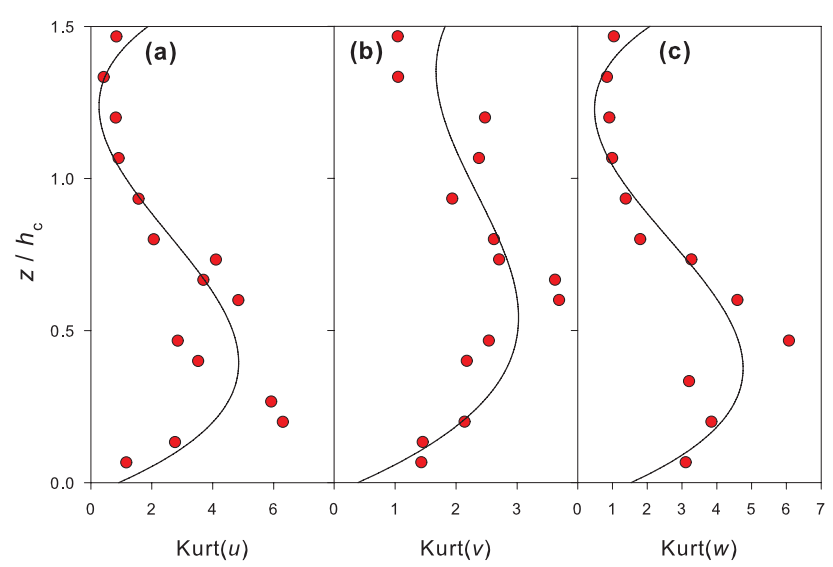

Fig. 10. Averaged profiles of the kurtosis of the individual wind components obtained with the small ultrasonic anemometer. A Gaussian distribution would have a kurtosis of 0 . The fitted curves are 3rd order polynomials. 


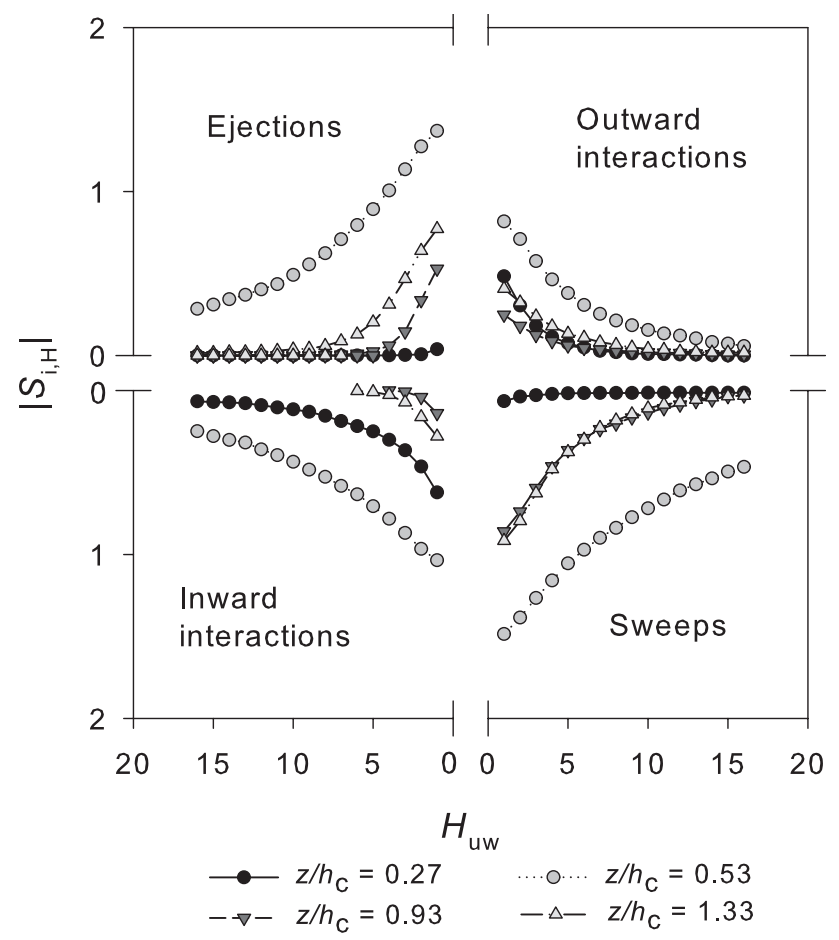

Fig. 11. Results of the quadrant hole analysis of the same 30-min periods presented in Fig. 8a-d. The figure shows the momentum carried by each type of interaction (i.e. sweep, ejection, inwardand outward-interaction) by extreme events exceeding the average momentum transfer by hole factor $H_{u w}$.

transferred in only $6 \%$ of the time (Fig. 12b). At the top of the canopy $u$ is significantly positively skewed, $w$ is somewhat negatively skewed and $v$ is near Gaussian (Fig. 9),

c) In the middle of the canopy $\left(z / h_{c}=0.40\right.$; Fig. $\left.8 \mathrm{c}\right)$, turbulence is much reduced with all quadrants contributing and no significant, co-ordinated momentum transfer occurs. Turbulence is less governed by extreme events (Fig. 11), resulting in an increasingly large value of $H_{1 / 2}$ (Fig. 12a). This implies that interactions start to make a large contribution to the momentum transport, which can be seen in the increase of exuberance (Fig. 12c). Half of the momentum is transferred in about $10 \%$ of the time (Fig. 12b).

d) In the bottom of the canopy $\left(z / h_{c}<0.30\right)$, variations in $w$ are more pronounced than variations in $u$ (Fig. 8d), indicating that transport processes become decoupled from the air flow above the canopy and dominated by buoyancy effects. The transport process most closely linked to extreme events appear to be the inward interactions. Compared with higher layers of the canopy, skewness and kurtosis are much reduced (Figs. 9 and 10), exuberance increase further, while half of the mo-

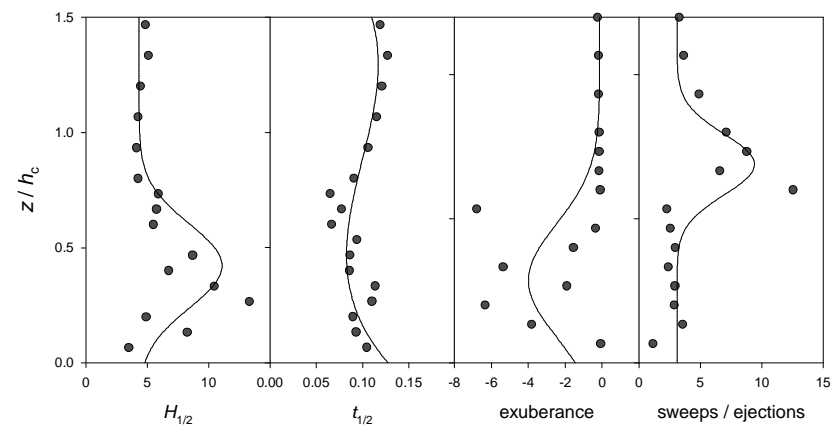

Fig. 12. Averaged profiles of the hole size at which half of the momentum transfer occurs $\left(H_{1 / 2}\right)$, the time fraction in which half of the momentum is transferred $\left(t_{1 / 2}\right)$, the ratio of interactions divided by the sum of sweeps and ejections (exuberance) and the ratio of sweeps to ejections as obtained with the miniature ultrasonic anemometer Also shows is a 3rd order polynomial fit for $t_{1 / 2}$ and Gaussian fits for the other parameters.

mentum is transferred within about $10 \%$ of the time $\left(t_{1 / 2} \sim 0.1\right) . H_{1 / 2}$ peaks around $z / h_{c}=1 / 3$ and decreases again towards the ground.

\section{Discussion}

\subsection{General turbulence statistics}

The normalised wind profiles showed a strong decrease towards the ground, without the second maximum, which is characteristic of canopies with a pronounced trunk space such as forests (cf. Gardiner, 1994), but has also been observed in some grass canopies (Wohlfahrt and Cernusca, 2002). The profiles of the 2 nd order moments $\sigma_{u} / u_{*}, \sigma_{v} / u_{*}$ and $\sigma_{w} / u_{*}$ showed very similar profiles, decreasingly sharply towards constant values of $0.26,0.29$ and 0.19 , respectively. Raupach et al. (1996) provided a comprehensive review of in-canopy variance profiles in the literature. Compared with parametrisations of $\sigma_{w} / u_{*}$ for crops, $\sigma_{w}$ declined more sharply in the top half of the canopy (Fig. 13a), but values of $\sigma_{w} / u_{*}$ are a little larger than previously reported for a grassland (Aylor et al., 1993). The near-surface values of all parametrisations are similar, with the exception of the results of the model by Massman and Weil (1999) applied to the grass canopy, which, using the parameters chosen here, over-predicts $\sigma_{w} / u_{*}$ throughout the canopy. A possible reason is an over-estimation in the length scale in the model parameterization, with $\alpha=0.01$ providing a better fit to the measurements (not shown). The parametrisation of Leuning et al. (2000) for rice agrees well in the lower half of the canopy, but under-predicts $\sigma_{w}$ at the top of the canopy and in the roughness layer. This may be linked to differences in the morphology of the canopies, with rice providing a larger 


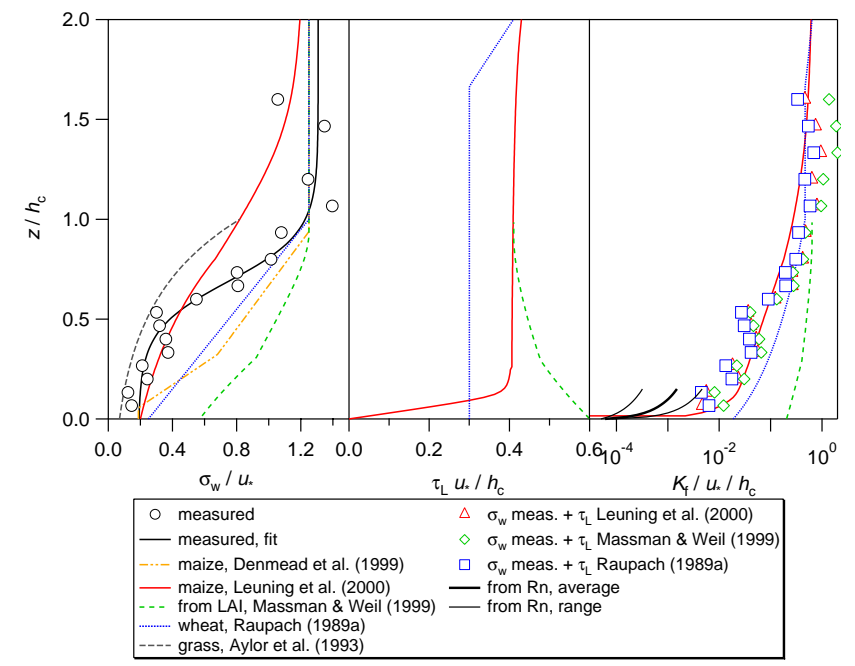

Fig. 13. Summary of parameterisations of (a) $\sigma_{w} / u_{*}$, (b) $\tau_{L}$ and (c) $K_{f}$ from the literature. The symbols in (c) represent combinations of the measured values of $\sigma_{w} / u_{*}$ and theoretically derived parameterisations of $\tau_{L}$ presented in the literature.

leaf area density at the top of the canopy, which, in the mixed mature grassland, is made up of a few flowers (Fig. 1).

Comparison of the total turbulence intensity $\left(e^{2}\right)$ measured with the miniature sonic anemometer with the results from the hot wire anemometer shows somewhat larger values towards the ground, which may indicate an increase in the turbulence in the space of the anemometer which had to be kept free of grass. However, the associated overestimation in $\sigma_{w} / u_{*}$ would be insufficient to explain the discrepancy with the paramametrisations.

\subsection{Gaussianity of the turbulence and effects of non- neutral conditions}

The higher-order moments of turbulence, kurtosis and skewness, provide a first indication of the degree of nonGaussianity in the plant canopy. In line with previous measurements and theoretical considerations, these measurements show more variability than the 2 nd order moments (e.g., Lenschow et al., 2000; Hong et al., 2002). $\mathrm{Sk}_{u}$ was positive throughout the canopy, with the largest values just above the half height of the canopy (Fig. 9a), while $\mathrm{Sk}_{w}$ converged to zero at the top and bottom of the canopy, with negative values at mid canopy (Fig. 9c) and $\mathrm{Sk}_{v}$ was close to 0 throughout (Fig. 9b). This behaviour is similar to the forest results of Green et al. (1995) and the wind-tunnel results in wheat of Brunet et al. (1994), except that they found $\mathrm{Sk}_{w}$ to become increasingly negative towards the ground. By constrast, Raupach et al. (1996) and Hong et al. (2002) reported small negative values of both $\mathrm{Sk}_{u}$ and $\mathrm{Sk}_{w}$ near the ground for forest and rice paddy, respectively, although the latter authors concede that the negative values of $\mathrm{Sk}_{u}$ may be an artefact due to local hollows and hummocks in the ground surface. Wilson et al. (1982) also reported non-zero skewness near the ground for a maize canopy. Kurtosis of all wind components showed small positive values (leptokurtosis) above the canopy, which peaked at mid canopy and decreased again towards the ground. The magnitude of $\mathrm{Kurt}_{u}$ and $\mathrm{Kurt}_{w}$ was similar and again closely resembled the forest results of Green et al. (1995). By contrast, Brunet et al. (1994) observed smaller values for Kurt ${ }_{u}$.

Two-parametric frequency distributions of $w^{\prime}-u^{\prime}$ and Q-H analyses have been presented before for taller canopies, including forests (e.g. Gardiner, 1994) and crops (e.g., Shaw et al., 1983; Hong et al., 2002). In a grassland, Aylor et al. (1993) observed quiescent periods (i.e., with wind speeds lower than the mean) for $62 \%$ of the time, while the probability density function of the extreme events of the wind speed $(s)$ measured with cup anemometers could be approximated by:

$f(s)=12.83 \sigma_{s}^{-1} \exp (-g(s)-\exp (-g(s)))$

with

$g(s)=1.283 \sigma_{s}^{-1}\left(s-\mu_{s}\right)+0.577$

Here $\mu_{s}$ and $\sigma_{s}$ are mean and standard deviation of $s$, respectively.

Above and in the upper half of the grass canopy, twoparametric frequency distributions of $u^{\prime}-w^{\prime}$ measured at Braunschweig are consistent with the previous measurements in taller canopies (Fig. 8a, b) (Amiro, 1990; Lee and Black, 1993): the momentum exchange is dominated by sweeps and ejections, the former representing the more extreme events, which is also reflected in the results of the Q$\mathrm{H}$ analysis (Fig. 11). At lower heights (e.g., $z / h_{c}=0.27$ ) the momentum flux is much reduced and the shape of the twoparametric frequency distribution depends on the comparative magnitudes of $u_{*}$ and $w_{*}$ (reflecting the magnitude of above-canopy turbulence and ground heat flux, respectively). The shape familiar from above-canopy measurements is only found deep in the dense grass canopy, if $G$ is negative (downwards, Fig. 8e). For positive $G\left(w_{*}>0\right)$ outward interactions become increasingly important (Fig. 8d, f) as $G$ increases, even if $u_{*}$ is large (Fig. 8d). This behaviour marks the transition from a rough boundary layer flow at the top of the canopy to a convective flow within the canopy when $G>0$, typically at night.

Despite this effect of $G$ on the frequency distribution of $w^{\prime}-u^{\prime}$, in-canopy profiles of $\sigma_{w} / u_{*}$ appeared to be fairly insensitive to atmospheric stability $(L)$ or ground heat flux $(G)$, within the error of the measurements (Fig. 3). Above the canopy $\sigma_{w} / u_{*}$ follows the dependence on $\zeta$ expected for fully developed turbulence, but inside the canopy the picture becomes more hazy (Fig. 4), with the measurements suggesting a slight decrease in $\sigma_{w}$ in stable conditions. The insensitivity to $L$ is consistent with the measurement results of Hong et al. (2002) for rice paddy, who found $\sigma_{w} / u_{*}$ to change with 
$L$ only at the canopy top and only during stable conditions. By contrast, Launiainen et al. (2007) reported significant enhancements of $\sigma_{w} / u_{*}$ within a boreal forest canopy under very stable night-time conditions and Shaw et al. (1988) observed that, in a mixed hardwood forest, stable stratification had a significant impact on the vertical profile of $\sigma_{w} / u_{\text {ref. }}$ In the latter study, this may in part be explained by the difference in normalisation because stability changes the relationship between $u_{\text {ref }}$ and $u_{*}$. However, the observed insensitivity to $L$ in the grassland canopy is consistent with decoupling of the in-canopy turbulence structure expected for short vegetation (e.g. Raupach et al., 1996). We are not aware of any other study that has tried to investigate the profile of $\sigma_{w} / u_{*}$ in relation to in-canopy stability (as related to $G$ or $w_{*}$ ), but the results here indicate that there is little effect, in line with the reasoning by Shaw et al. (1988).

Apparently inconsistent with the results of Hong et al. (2002), Leuning (2000) applied a stability correction in the application of the inverse Lagrangian model in the same rice study. This correction predicted larger values of $\sigma_{w}$ in stable and unstable conditions, and is therefore not supported by our measurements. However, the major influence of stability on in-canopy transport was through its effect on $\tau_{L}$, which could not be investigated in this study.

The vertical profile of the ratio sweeps/ejections (Fig. 12c) is similar to that observed in the rice paddy of Hong et al. (2002) and maize canopy by Shaw et al. (1983), with the largest values towards the canopy top and a flat profile further down. However, absolute values of this ratio are larger in the grass canopy (3-9) than in the maize and rice paddy (1-3). Similarly, the profiles of exuberance found in this study (Fig. 12b) were similar to those reported by Hong et al. (2002) (who presented 1/exuberance as defined here).

\subsection{Comparison of transport coefficients from anemom- etry and Radon tracer technique}

In order to derive the within canopy turbulent diffusivity $\left(K_{f}(z)\right)$ from turbulence measurements (Eq. 6), vertical profiles of $\sigma_{w}$ need to combined with profiles of $\tau_{L}$. Profiles of $\tau_{L}(z)$ cannot be derived from single point measurements and are currently highly speculative. In particular, there is uncertainty whether $\tau_{L}$ increases or decreases close to the ground. Figure 13b demonstrates the range of parameterisations currently advocated in the literature. The measured values of $\sigma_{w} / u_{*}$ from Figs. 2d and 13a may be combined with these $\tau_{L}$ profiles to derive estimates of the far-field diffusivities (Fig. 13c). The mean (black bold solid line) and the range (black thin solid lines) of $K_{f}$ values derived with the $\mathrm{Rn}$ tracer technique are shown in Fig. 13c for comparison. The model of Massman and Weil (1999) applied to the grass canopy not only predicts the largest values of $\sigma_{w}$, but also combines these with the largest values of $\tau_{L}$, resulting in large values of $K_{f}$ near the ground which are not supported by our measurements. While the magnitude of $\sigma_{w}$

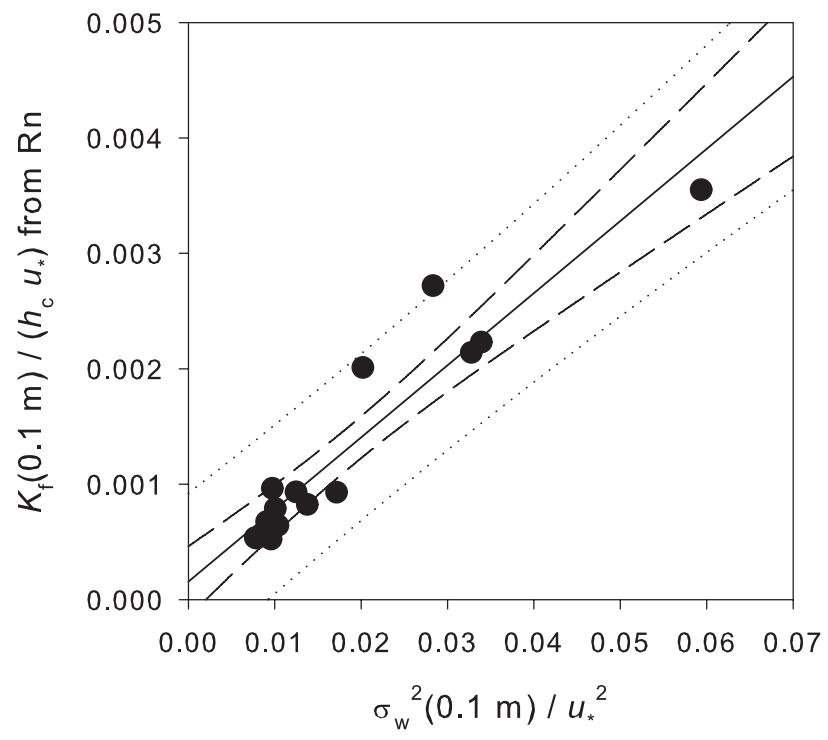

Fig. 14. Relationship between normalized far-field diffusivity $\left(K_{f}(0.1 \mathrm{~m})\right)$ derived from the $\mathrm{Rn}$ tracer technique and the normalized standard deviation of the vertical wind component $\left(\sigma_{w}\right)$ from the miniature ultrasonic anemometer for hourly values during the period the anemometer was operated at $z=0.1 \mathrm{~m}\left(R^{2}=0.89, N=15\right.$, $P<0.001)$. Dashed lines are $95 \%$ confidence and prediction bands.

depends on the choice of the model parameters, the increase of $\tau_{L}$ is model inherent. The parametrisation of Raupach et al. (1989) also over-predicts $K_{f}$ due to a larger estimate of $\sigma_{w}$. The $\tau_{L}$ parametrisation of Leuning et al. (2000) predicts the lowest values at the bottom measurement height and, interpolated to the ground, is the only parametrisation that is in the range of the Rn measurements, although the shape is considerably different. The shape of the Rn derived $K_{f}$ profile was arbitrarily fixed through assumption that it is linear with height (Eq. 10), while the $\tau_{L}$ parametrisation of Leuning et al. (2000) implies a near exponential increase in $K_{f}$ with height near the ground. This non-linearity of $K_{f}$ near the ground is further supported e.g. by $K_{f}$ profiles in maize measured by Druilhet (1970), who derived s-shaped profiles during the night, from thoron measurements at eight heights. Indeed, comparison of the activities predicted by the linear model with the measurements at the different heights shows good agreement at $2 \mathrm{~cm}$, but an overestimation of activities at $15 \mathrm{~cm}$ (not shown). This suggests that the actual transport above $2 \mathrm{~cm}$ is faster than predicted based on a linear relationship. Thus, the non-linear function of $\tau_{L}(z)$ with very low values close to the ground is likely to be a better reflection of the actual profile and the Leuning et al. (2000) parameterisation appears to be in reasonable agreement with the measurement based evidence.

The relationship of the normalized $K_{f}(0.1 \mathrm{~m})$ derived by $\mathrm{Rn}$ tracer technique and $\sigma_{w}^{2}$ measured with the miniature ultrasonic anemometer is depicted in Fig. 14. The slope of the correlation line of 0.062 may be identified with the average 
of $\tau_{L} u_{*} / h_{c}$ over the height range of the Rn measurements, and the good linear fit implies that this parameter is relatively constant with time, while $\sigma_{w} / u_{*}$ shows significant variation. This estimation of $\tau_{L}(0.1 \mathrm{~m}) u_{*} / h_{c}$ is well within the range reported by Poggi et al. (2006) who also derived relative small values ranging from 0.045 and 0.1 within the canopy space. It is intriguing that the intercept of $1.6 \times 10^{-4}$, evaluated for the average value of $u_{*}$ during these measurements $\left(0.19 \mathrm{~m} \mathrm{~s}^{-1}\right)$, results in a value of $K_{0}=2.0 \times 10^{-5} \mathrm{~m}^{-2} \mathrm{~s}^{-1}$, close to the molecular diffusivity of $\operatorname{Rn}\left(1.2 \times 10^{-5} \mathrm{~m}^{-2} \mathrm{~s}^{-1}\right)$.

According to Heinz and Schaller (1996) a non-zero kurtosis would increase the apparent diffusivity. They calculated that diffusivity $K_{f}(z)$ would be increased by a factor $\left(\operatorname{Kurt}_{w}+4\right) / 4$, which represents an increase ranging from $25 \%$ to $75 \%$ within the canopy for Kurt ${ }_{w}=1$ and $\mathrm{Kurt}_{w}=4$, respectively (Figure 10). Similarly, Heinz and Schaller (1996) showed that a skewed distribution would increase the diffusivity by a factor $\left(1+\mathrm{Sk}_{w}^{8}\right)$, which represents a $0.4 \%$ or a $100 \%$ increase for $\mathrm{Sk}_{w}=-0.5$ and $\mathrm{Sk}_{w}=-1$ respectively (Fig. 9). Their estimation for the skewed distribution is very sensitive to $\mathrm{Sk}_{w}$ in the range $0.5-1.0$, but our measurement suggests it should be lower than 0.5 in most part of the canopy, hence leading to a negligible increase in $K_{f}(z)$. These calculations from Heinz and Schaller (1996) are based on parameterised distribution and should be taken with caution. They nevertheless may indicate that the apparent diffusivity may be larger than that evaluated from $\sigma_{w}$ profiles and $\tau_{L}$ parametarisation in the middle canopy, but may be identical at the bottom canopy where $\mathrm{Sk}_{w}$ tends toward 0 .

Strictly speaking, $K_{f}(z)$ can only be linked to $\sigma_{w}$ and $\tau_{L}$ (Eq. 6) if the turbulence is homogeneous and isotropic or if the "time of travel" of the fluid parcels from their "source" is larger than $2 \tau_{L}$ (e.g. Rodean, 1996). In a dense canopy such as the grassland canopy, this formulation would hence apply if the fluid parcels were at distances larger than $z \sim 2 \tau_{L} \sigma_{w}$. Using the standard formulation of $\tau_{L}=0.4 h_{c} / u_{*}$ and $\sigma_{w}=0.2 u_{*}$ (Fig. 13), then $z=2 \times 0.4 h_{c} / u_{*} \times 0.2 u_{*}=0.16 h_{c}$ away from their sources. Using $h_{c}=0.1$ to 0.7 , this gives an order of magnitude of $z \sim 2$ to $10 \mathrm{~cm}$ away from the source. Moreover, Sawford (1984) showed by comparing random-flight predictions with diffusion-equation that Eq. (6) holds only for moderate inhomogeneity index $I=\partial_{z}\left[\sigma_{w}^{-1}(\mathrm{z}) K_{f}(\mathrm{z})\right](I<0.4)$. He showed that for $I>2$, Eq. (6) does not hold. The radon tracer measurements indicate $K_{z}=\partial_{z} K_{f}(\mathrm{z}) \sim 0.06 \mathrm{~m} \mathrm{~s}^{-1}$ near the ground, and $\sigma_{w}$ of the order $0.2 u_{*}$ and constant near the ground, hence implying an inhomogeneity index of $I \sim 0.3 / u_{*}$. Hence, the hypothesis of weakly inhomogeneous turbulence should be satisfied only for $u_{*}>0.75 \mathrm{~m} \mathrm{~s}^{-1}$, which occurred rarely during the measurement period. Instead, for $u_{*} \sim 0.3 \mathrm{~m} \mathrm{~s}^{-1}, I$ would be of the order of 1 , and hence the definition of $K_{f}(\mathrm{z})$ of Eq. (6) should not be fully applicable, which would provide a further explanation for a mismatch between $K_{f}(z)$ from the Radon technique and evaluation with Eq. (6) (cf. Raupach, 1989, for further discussion).
Since $\tau_{L}$ may also be expressed as $\tau_{L}=2 \sigma_{w}^{2} /\left(C_{0} \varepsilon\right)$. Taking $C_{0}=3.12$ (Loubet et al., 2006) and $\sigma_{w}=0.2 u_{*}$ implies that, near the ground, $\varepsilon=0.4 u_{*}^{3} / h_{c}$, which is around 6 times smaller than $\varepsilon$ at $z=2 h_{c}$ (e.g. Kaimal and Finnigan, 1994). Poggi et al. (2006) found in a wind-tunnel experiment $\varepsilon=0.7 u_{*}^{3} / h_{c}$ at the ground from "measurements" of $\varepsilon$ estimated from the isotropic and homogeneous relationship, while they found $\varepsilon=0.3 u_{*}^{3} / h_{c}$ from inferring $\varepsilon$ from the integral time scale for vertical velocity, and they found $\varepsilon=0.5 u_{*}^{3} / h_{c}$ when using the Lagrangian time scale.

In summary, the combined measurements with anemometry and Radon tracer technique provide important information on diffusive time-scales near the ground and sheds light on processes in the unresolved basal layer. The measurements reveal that they are made in a regime where Eq. (6) is not fully valid to link $K_{f}$ to $\sigma_{w}$ and $\tau_{L}$. However, if this equation is used, the measurements imply that $\tau_{L}$ must be small near the ground, which is consistent with Leuning et al. (2000) and Poggi et al. (2006), but contrary to the profiles proposed by Raupach (1989) as well as Massman and Weil (1999). This is supported by the work of Wohlfahrt (2004) who found better agreement between modelled and measured concentration profiles, when using a parametrisation of $\tau_{L}$ which did not increase towards the ground. Although the Rn approach derives appropriate average $K_{f}(z)$ values for the bottom $15 \mathrm{~cm}$ of the canopy, it appears not to predict the correct vertical structure, which is likely to consist of smaller values near the ground and larger values away from the ground, similar to the shape of $K_{f}(z)$ predicted by Leuning et al. (2000). The Rn measurements suggest an average value of $\tau_{L} u_{*} / h_{c}$ in the bottom of the canopy of 0.062 .

\subsection{Implications for tracer transport in the grass canopy}

\subsubsection{Time scales}

The Radon measurements reveal that average residence times of tracers emitted from the ground in the grass canopy are considerable, with transport in the lowest $15 \mathrm{~cm}$ taking 40 to $200 \mathrm{~s}$ in the tall and 10 to $100 \mathrm{~s}$ in the short canopy. This provides sufficient time for many reactions to become important (e.g. Foken et al., 1995). For example, chemical time-scales for the evaporation and formation of $\mathrm{NH}_{4} \mathrm{NO}_{3}$ are of the order of 1 to $10 \mathrm{~s}$ (e.g. Nemitz et al., 2004). Similarly, this time allows a considerable amount of soil derived NO to be converted to $\mathrm{NO}_{2}$ which may then partially be re-captured by the overlying canopy. Although grasslands are not thought to be a major source of the semi-volatile organic compounds indicated in the production of biogenic secondary organic aerosol (Kirstine et al., 1998), time-scales in other smooth vegetation are likely to be similar. By comparison, residence times in forests are not necessarily longer than observed in the grassland; e.g. Goldstein et al. (2004) reported a residence time of $90 \mathrm{~s}$ for a relatively sparse Californian pine forest. 


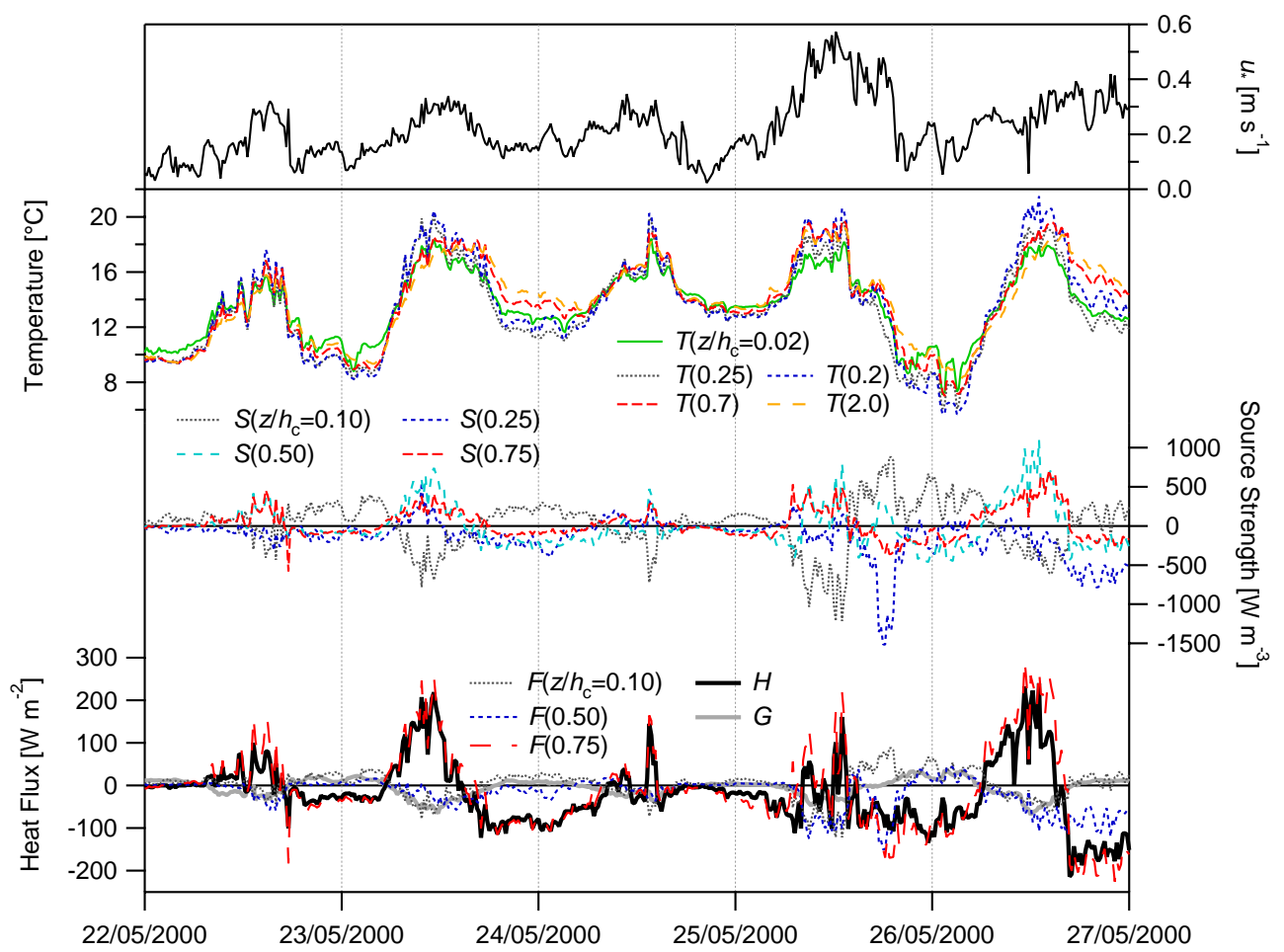

Fig. 15. Application of the Inverse Lagrangian Technique to derive sources and sinks of sensible heat in the grass canopy. (a) Measured friction velocity $\left(u_{*}\right)$ according to best estimate; (b) measured temperature profiles (selected heights); (c) source/sink strength (height refers to the top of the layer); (d) Sensible heat fluxes at different heights derived from the ILT $(F(z))$ compared with measurements of sensible heat flux above the canopy $(H)$ and the ground heat flux $(G)$.

\subsubsection{Sources and sinks of sensible heat}

The inverse Lagrangian technique (ILT) of Raupach (1989) as implemented by Nemitz et al. (2000a) was applied to the grassland canopy to test the performance of this approach with the understanding of the in-canopy transport processes. Based on the analysis above, $\sigma_{w} / u_{*}$ was parameterised according to Table 1 and $\tau_{L}$ according to Leuning (2000), Fig. 13b. Stability effects were not taken into account. The values of $u_{*}$ were taken from the best-estimate dataset, derived as an average of up to eight ultrasonic anemometers (Nemitz et al., 2009). These measurements showed an average relative standard deviation of $13.8 \%$, but the standard deviation of the campaign averages was as low as $0.7 \%$. This indicates that most of the uncertainty was due to spatial heterogeneity in the turbulence, and thus the averaging of several anemometers should provide a much more robust estimate. Two independent temperature profiles were recorded at two locations at the main measurement site by CEH and INRA as described in Sect. 2.3. The analysis presented here is based on the INRA profile; the CEH profile provided similar results. Figure 15 summarises selected input data (measured temperature gradients) and the source/sink strengths in four specified layers (with upper boundaries of $0.10,0.25$, 0.5 and $0.75 \mathrm{~m}$ ) predicted by the ILT analysis. It also shows the resulting heat fluxes at the top of each source/sink layer, calculate as the accumulated source/sink strength up that height, in comparison to the measurements of sensible heat flux and ground heat flux (cf. Nemitz et al., 2009).

The above-canopy flux predicted by the ILT, based on characterisation of the in-canopy temperature gradient and the in-canopy turbulence $(F(0.75 \mathrm{~m}))$ agrees very well with the micrometeorological measurement of above canopy sensible heat flux $(H)$, although it slightly over-estimates positive heat fluxes during the days of 22 and 25-May, and slightly over-estimates negative heat fluxes during the last two nights of this example time-series. In this application of the ILT, the ground heat flux was not prescribed and is therefore included in the derived source/sink strength of the bottom height. Indeed, there is very reasonable agreement between $F(0.10 \mathrm{~m})$ and $G$, considering that this height layer also includes the effect of the lowest layer of vegetation in addition to the ground heat flux. The agreement suggests that the in-canopy turbulence is adequately described by the chosen parameterisations of $\sigma_{w}$ and $\tau_{L}$.

\subsubsection{In-canopy sources of ammonia}

The focus of the GRAMINAE experiment at Braunschweig was the study of the sources and sinks of ammonia in an 


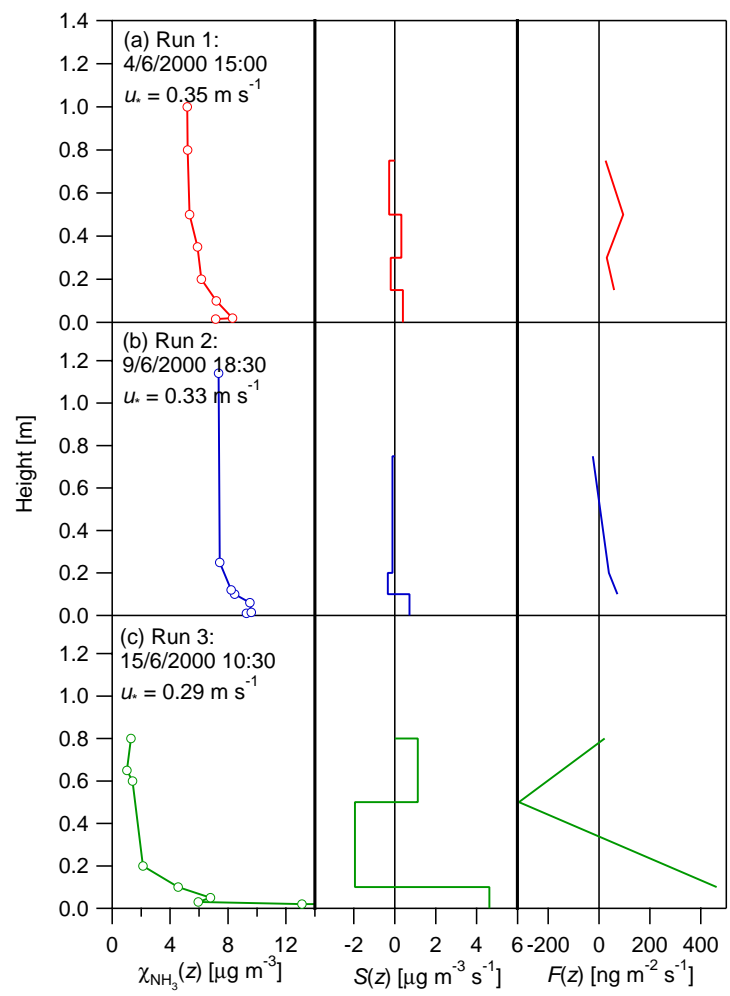

Fig. 16. Vertical profiles of ammonia measured in the tall grass canopy with the fast $\mathrm{NH}_{3}$ sensor, showing measured concentrations $\left(\chi \mathrm{NH}_{3}(z)\right)$ as well as derived source/sink profiles $(S(z))$ and the cumulative fluxes at the top of each source/sink layer $(F(z))$.

agricultural grassland and their response to management such as cutting and fertilisation. This was achieved through the combination of flux measurements at the canopy scale (Milford et al., 2008; Hensen et al., 2008a), direct measurement of the plant physiological emission potentials (Mattsson et al., 2009a, b; Herrmann et al., 2009) model simulations (Burkhardt et al., 2009; Personne et al., 2009; Sutton et al., 2009b) and flux chamber measurements on small plots with management variations (David et al., 2009a, b). The canopy scale fluxes showed that the cut of the grassland induced increased ammonia emission fluxes consistent with previous observations (Milford et al., 2001). These were previously attributed to increased foliar $\mathrm{NH}_{3}$ compensation points following the concentration of $\mathrm{NH}_{4}^{+}$within the leaf apoplast, linked to a shortage of plant substrate carbon after the cut (Riedo et al., 2002). However, overall the evidence of the measurements at Braunschweig suggests that this emission originates from senescent plant material, which is located near the ground and exposed to the atmosphere after the cut (Sutton et al., 2009b). If this is true, these sources should already exist in the tall canopy before the cut. Nevertheless, they may have been smaller for several reasons: (a) turbulence was reduced compared with the cut canopy, flushing less of the emitted $\mathrm{NH}_{3}$ out of the canopy, result- ing in a build-up of the concentration and a reduction in the emission from compensation points, (b) the temperature was lower than after the cut, resulting in smaller compensation points and (c) cutting itself will have increased senescence of remaining leaves (Sutton et al., 2009b). Although senescent emissions is expected to have occurred, any emission from senescing plant parts would need to have been re-captured by the overlying canopy to explain the small net emission and deposition fluxes before the cut, similar to the canopy cycling previously found for oilseed rape (Nemitz et al., 2000a, b).

Figure 16 shows the $\mathrm{NH}_{3}$ profiles measured with the fastresponse $\mathrm{NH}_{3}$ sensor as described in Sect. 2.3. Because these profile measurements were made above the small uncut setaside plot after cut of the main field, the fluxes derived from the in-canopy measurements cannot be compared with the gradient flux measurements on the main field. However, the results nevertheless shed light on the in-canopy cycling of $\mathrm{NH}_{3}$ in the tall grass prior to cutting.

The exact source/sink profiles are dependent on the definition of the source/sink layers, which were chosen to reflect the measured concentration layers. However, reflecting the shape of the in-canopy profiles, all vertical source/sink distributions show a source (positive value) near the ground. This feature is independent of the specification of the layers and supports that there was indeed a ground-level $\mathrm{NH}_{3}$ source at the bottom of the canopy, consistent with emissions from the ground, such as from senescent plant material, leaf litter or the soil surface. Based on the three runs available, estimated emissions at the top of the canopy were 50\%,0\% (actually net deposition) and $7 \%$ of the emissions at $0.1-0.15 \mathrm{~m}$ above ground, highlighting the potential of the overlaying canopy to recapture most of the ground source ammonia emission.

\section{Conclusions}

Anemometer measurements of in-canopy turbulence are combined with information derived from in- and abovecanopy Radon measurements to gain insights into the turbulent structure and transport mechanisms in a tall agricultural grass canopy, with focus on turbulence near the ground and non-Gaussianity of the turbulence. Measurements of the standard deviation of the vertical wind component, normalized by friction velocity $\left(\sigma_{w} / u_{*}\right)$ decline more sharply towards the ground than most parametrisations for crops, but values are somewhat higher than previously observed for a grass canopy. The formulation of Massman and Weil (1999) to derive $\sigma_{w}$ and $\tau_{L}$ from the vertical leaf area density profile failed to describe either parameter correctly. Turbulence within the canopy was found to be moderately heterogeneous; quadrant-hole analysis and higher order moments indicate that it was significantly non-Gaussian. This suggests that the approach to parametrize the far field turbulent diffusion coefficient $\left(K_{f}(z)\right)$ as the product of $\sigma_{w}^{2}$ and the Lagrangian timescale $\left(\tau_{L}\right)$ is not ideal. However, if this 
approach is used, a parametrisation needs to be applied for $\tau_{L}$ which declines sharply towards the ground in order to reconcile the anemometer-based turbulence measurements with the Radon based transport coefficients, e.g. of the form of the parametrisation suggested by Leuning et al. (2000). As a consequence transport in the basal layer near the ground is slower than predicted by most previously used parametrisations of $\tau_{L}$, in agreement with the conclusions of Poggi et al. (2006). Not only does this impact on ground level emissions derived by inverse Lagrangian approaches, but it also shows that compounds emitted from the soil surface have additional time to undergo chemical transformations.

The measurement based parameterization of $\sigma_{w}$ together with the Leuning et al. (2000) formulation for $\tau_{L}$ performs well within the analytical inverse Lagrangian framework of Raupach (1989) for temperature: sensible heat fluxes derived from in-canopy temperature profiles match both the measured net flux above the canopy and the measured ground heat flux. Although in-canopy measurements of ammonia are somewhat uncertain, the source profiles derived from the validated Lagrangian approach indicate that there is a strong source in the bottom of the canopy, which is mainly recaptured by the overlying grass canopy. This is consistent with senescent leaves/leaf litter in the bottom of the canopy acting as an ammonia source. This emission is thought to be responsible for sustained $\mathrm{NH}_{3}$ emissions after grass cutting, as indicated by independent bioassay and chamber measurements summarized elsewhere (Sutton et al., 2009b).

Acknowledgements. This work was funded by the EU projects GRAMINAE and NitroEurope IP as well as national funding from the UK Department of Environment, Food and Rural Affairs (Defra) and its devolved UK administrations and the French Ministry of Research and Education and the French Ministry of Agriculture. The fast response $\mathrm{NH}_{3}$ sensor used for the in-canopy profile measurements was developed by Pavel Mikuška, Institute of Analytical Chemistry, ASCE, Brno, Czech Republic.

Edited by: J. K. Schjoerring

\section{References}

Amiro, B. D.: Comparison of turbulence statistics within three boreal forest canopies, Bound.-Lay. Meteorol., 51(1-2), 99-121, 1990.

Aylor D. E., Wang Y., and Miller D. R.: Intermittent wind close to the ground within a grass canopy, Bound.-Lay. Meteorol., 66, 427-448, 1993.

Baldocchi D.: A Lagrangian random-walk model for simulating water vapour, $\mathrm{CO}_{2}$ and sensible heat flux densities and scalar profiles over and within a soybean canopy, Bound.-Lay. Meteorol., 61, 113-144, 1992.

Brunet, Y., Finnigan, J. J., and Raupach, M. R.: A wind tunnel study of air flow in waving wheat: single-point velocity statistics, Bound.-Lay. Meteorol., 70, 92-132, 1994.

Brunet, Y. and Collineau, S.: Wavelet analysis of diurnal and nocturnal turbulence above a maize crop. In: Efi Foufoula-Georgiou and Praveen Kumar (eds.) Wavelets in Geophysics, Academic Press, New York, 129-150, 1994.

Buresti, G. and Talamelli, A.: On the Error Sensitivity of Calibration Procedures for Normal Hot-Wire Probes, Measurement Sci. Technol., 3(1), 17-26, 1992.

Burkhardt, J., Flechard, C. R., Gresens, F., Mattsson, M. E., Jongejan, P. A. C., Erisman, J. W., Weidinger, T., Meszaros, R., Nemitz, E., and Sutton, M. A.: Modelling the dynamic chemical interactions of atmospheric ammonia with leaf surface wetness in a managed grassland canopy, Biogeosciences, 6, 67-83, 2009, http://www.biogeosciences.net/6/67/2009/.

Ciccioli, P., Brancaleoni, E., Frattoni, M., Di Palo, V., Valentini, R., Tirone, G., Seufert, G., Bertin, N., Hansen, U., Csiky, O., Lenz, R., and Sharma, M.: Emission of reactive terpene compounds from orange orchards and their removal by within-canopy processes, J. Geophys. Res., 104(D7), 8077-8094, 1999.

David, M., Loubet, B., Cellier, P., Mattsson, M., Schjoerring, J. K., Nemitz, E., Roche, R., Riedo, M., and Sutton, M. A.: Ammonia sources and sinks in an intensively managed grassland using dynamic chambers, Biogeosciences Discuss., 6, 1625-1655, 2009a, http://www.biogeosciences-discuss.net/6/1625/2009/.

David, M., Roche, R., Mattsson, M. E., Sutton M. A., Dämmgen, U., Schjoerring, J. K., and Cellier, P.: The effects of management on ammonia fluxes over a cut grassland as measured by use of dynamic chambers, Biogeosciences Discuss., 6, 1599-1623, 2009b, http://www.biogeosciences-discuss.net/6/1599/2009/.

Denmead O. T.: Novel micrometeorological techniques, Phil. Trans. Roy. Soc. Lond. A, 351, 383-396, 1995.

Denmead, O. T. and Raupach, M. R.: Methods for measuring atmospheric gas transport in agricultural and forest systems. Agric. Ecosystem Effects on Trace Gases and Global Climate Change, ASA Special Pub., 55, 19-43, 1993.

Denmead, O. T., Harper, L. A., and Sharpe, R. R.: Identifying sources and sinks of scalars in a corn canopy with invserse Lagrangian dispersion analysis. I. Heat, Agric. For, Meteorol., 104, 67-73, 2000.

Denmead, O. T., Freney, J. R., and Dunin, F. X.: Gas exchange between plant canopies and the atmosphere: Case-studies for ammonia, Atmos. Environ., 42(5), 3394-3406, 2008.

Druilhet, A.: Détermination de la diffusivité turbulente dans les premieres mètres au-dessus du sol a partir de la diffusion du thoron. In : Techniques d'étude des facteurs physiques de la biosphère, I.N.R.A., Publ. 70-4, Institute Nationale de la Recherche Agronomique, 149, rue de Grenelle, Paris-7e, 1970.

Finnigan, J.: Tubulence in plant canopies, Annu. Rev. Fluid. Mech., 32, 519-571, 2008.

Foken, T., Dlugi, R., and Kramm, G.: On the determination of dry deposition and emission of gaseous compounds at the biosphereatmosphere interface, Meteorologische Zeitschrift, 4(3), 91, 1995.

Gardiner, B. G.: Wind and wind forces in a plantation spruce forest, Bound.-Lay. Meteorol., 67, 161-186, 1994.

Gardiner, B. G.: The interactions of wind and tree movement in forest canopies. in: Wind and Trees, edited by: Coutts, M. P. and Grace, J., Cambridge University Press, 485 pp., 1995.

Garland, J. A.: The dry deposition of sulphur dioxide to land and water surfaces, Proc. Roy. Soc. Lond. A, 354, 245-268, 1977.

Goldstein, A. H., McKay, M., Kurpius, M. R., Schade, G. W., Lee, A., Holzinger, R., and Rasmussen, R. A.: Forest thinning experi- 
ment confirms ozone deposition to forest canopy is dominated by reaction with biogenic VOCs, Geophys. Res. Lett., 31, L22106, doi:10.1029/2004GL021259, 2004.

Green, S. R., Grace, J., and Hutchings, N. J.: Observations of turbulent air flow in three stands of widely spaced Sitka spruce, Agr. For. Meteorol., 74, 205-225, 1995.

Harper, L. A., Denmead, O. T., and Sharpe, R. R.: Identifying sources and sinks of scalars in a corn canopy with invserse Lagrangian dispersion analysis. II. Ammonia, Agr. For Meteorol., 104, 75-83, 2000.

Heinz, S. and Schaller, E.: On the influence of non-Gaussianity on turbulent transport, Bound.-Lay. Meteorol., 81(2), 1573-1472, 1996.

Hensen, A., Nemitz, E., Flynn, M. J., Blatter, A., Jones, S. K., Sørensen, L. L., Hensen, B., Pryor, S., Jensen, B., Otjes, R. P., Cobussen, J., Loubet, B., Erisman, J. W., Gallagher, M. W., Neftel, A., and Sutton, M. A.: Inter-comparison of ammonia fluxes obtained using the Relaxed Eddy Accumulation technique, Biogeosciences Discuss., 5, 3965-4000, 2008a,

http://www.biogeosciences-discuss.net/5/3965/2008/.

Herrmann, B., Mattsson, M., Jones, S., Cellier, P., Milford, C., Sutton, M. A., Schjoerring, J. K., and Neftel, A.: Vertical structure and diurnal variability of ammonia exchange potential within an intensively managed grass canopy, Biogeoschiences, 6, 15-23, 2009.

Hirst, W. and Harrison, G. E.: The diffusion of radon gas mixtures, Proc. R. Soc. Lond. A, 169, 573-586, 1939.

Hong, J., Kim, J., Miyata, A., and Harazono, Y.: Basic characteristics of canopy turbulence in a homogenous rice paddy, J. Geophys. Res., 107(D22), 4623, doi:10.1029/2002JD002223, 2002.

Kaimal, J. C. and Finnigan, J. J.: Atmospheric boundary layer flows: Their structure and measurement, Oxford University Press, 289 pp., 1994.

Karl, T., Potosnak, M., Guenther, A., Clark, D., Walker, J., Herrick, J. D., and Geron, C.: Exchange processes of volatile organic compounds above a tropical rain forest: implications for modeling tropospheric chemistry above dense vegetation, J. Geophys. Res., 109, D18306, doi:10.1029/2004JD004738, 2004.

Katul, G., Oren, R., Ellworth, D., Hsieh, C.-I, Philips, N. and Lewin, K.: A Lagrangian dispersion model for predicting $\mathrm{CO}_{2}$ sources, sinks, and fluxes in a uniform loblolly pine (Pinus taeda L.) stand, J. Geophys. Res., 102, 9309-9321, 1997.

Katul, G. G., Leuning, R., Kim, J., Denmead, O. T., Miyata, A., and Harazono, Y.: Estimating $\mathrm{CO}_{2}$ source/sink distributions within a rice canopy using higher-order closure models, Bound.-Lay. Meteorol., 98, 103-125, 2001.

Kirstine, W., Glabally, I., Ye, Y., and Hooper, M.: Emissions of volatile organic compounds (primarily oxygenated species) from pasture, J. Geophys. Res., 103(D9), 10605-10619, 1998.

Launiainen, S., Vesala, T., Mölder, M., Mammarella, I., Smolander, S., Rannik, Ü., Kolari, P., Hari, P., Lindroth, A., and Katul, G. G.: Vertical variability and effect of stability on turbulence characteristics down to the floor of a pine forest, Tellus 59B, 919-936, 2007.

Leclerc, M. Y., Beisner, K. C., Shaw, R. H., den Hartog, G., Neumann, H. H.: The influence of buoyancy on third-order turbulent velocity statistics within a deciduous forest, Bound.-Lay. Meteorol., 55, 109-123, 1991.

Lee, X. and Black, A.: Atmospheric turbulence within and above a Douglas-fir stand. Part I: Statistical properties and the velocity field, Bound.-Lay. Meteorol. 64, 149-174, 1993.

Lenschow, D. H., Wulfmeyer, V., and Senff, C.: Measuring secondthrough fourth-order moments in noisy data, J. Atmos. Ocean. Technol., 17(10), 1330-1347, 2000.

Lehmann, B. E., Lehmann, M., Neftel, A., Gut, A., and Tarakanov, S. V.: Radon-220 calibration of near-surface turbulent gas transport, Geophys. Res. Lett., 26(5), 607, doi:10.1029/1999GL900026, 1999.

Lehmann, B. E., Lehmann, M., Neftel, A., and Tarakanov, S. V.: Radon-222 monitoring of soil diffusivity, Geophys. Res. Lett., 27(23), 3917-3920, 2000.

Leuning, R.: Source/sink distributions in plant canopies using Lagrangian dispersion analysis: corrections for atmospheric stability and comparison with a canopy model, Bound.-Lay. Meteorol. 96(1-2), 293-314, 2000.

Leuning, R., Denmead, O. T., Miyata, A., and Kim, J.: Source/sink distributions of heat, water vapour, carbon dioxide and methane in a rice canopy estimated using Lagrangian dispersion analysis, Agric. Forest Meteorol., 104(3), 233-249, 2000.

Loubet, B., Cellier, P., Milford, C., and Sutton, M. A.: A coupled dispersion and exchange model for short-range dry deposition of atmospheric ammonia, Q. J. Roy. Meteor. Soc., 132, 1733-1763, 2006.

Massman, M. J. and Weil, J. C.: An analytical one-dimensional second-order closure model of turbulence statistics and the Lagrangian time scale within and above plant canopies of arbitrary structure, Bound.-Lay. Meteorol., 91, 81-107, 1999.

Makar, P. A., Fuentes, J. D., Wang, D., Staebler, R. M., and Wiebe, H. A.: Chemical processing of biogenic hydrocarbons within and above a temperate deciduous forest, J. Geophys. Res., 104(D3), 3581-3603, 1999.

Mattsson, M., Herrmann, B., Jones, S., Neftel, A., Sutton, M. A., and Schjoerring, J. K.: Contribution of different grass species to plant-atmosphere ammonia exchange in intensively managed grassland, Biogeosciences, 6, 59-66, 2009a, http://www.biogeosciences.net/6/59/2009/.

Mattsson, M., Herrmann, B., David, M., Loubet, B., Riedo, M., Theobald, M. R., Sutton, M. A., Bruhn, D., Neftel, A., and Schjoerring, J. K.: Temporal variability in bioassays of the stomatal ammonia compensation point in relation to plant and soil nitrogen parameters in intensively managed grassland, Biogeosciences, 6, 171-179, 2009b, http://www.biogeosciences.net/6/171/2009/.

Merry, M. and Panofsky, H. A.: Statistics of vertical motion over land and water, Q. J. Roy. Meteorol. Soc., 102, 255-260, 1976.

Milford, C., Theobald, M. R., Nemitz, E., and Sutton, M. A.: Dynamics of ammonia exchange in response to cutting and fertilizing in an intensively-managed grassland, Water Air Soil Poll. Focus, 1(5-6), 1573-2940, 2001.

Milford, C., Theobald, M. R.., Nemitz, E., Hargreaves, K. J., Horvath, L., Raso, J., Dämmgen, U., Neftel, A., Jones, S. K., Hensen, A., Loubet, B., Cellier, P., and Sutton, M. A.: Ammonia fluxes in relation to cutting and fertilization of an intensively managed grassland derived from an inter-comparison of gradient measurements, Biogeosciences Discuss., 5, 4699-4744, 2008, http://www.biogeosciences-discuss.net/5/4699/2008/.

Nemitz, E. and Sutton, M. A.: Gas-particle interactions above a Dutch heathland: III. Modelling the influence of the $\mathrm{NH}_{3}-$ 
$\mathrm{HNO}_{3}-\mathrm{NH}_{4} \mathrm{NO}_{3}$ equilibrium on size-segregated particle fluxes, Atmos, Chem, Phys., 4, 1025-1045, 2004.

Nemitz, E., Sutton, M. A., Gut, A., San José, R., Husted, S., and Schjørring, J. K.: Sources and sinks of ammonia within an oilseed rape canopy, Agr. For. Meteorol., 105(2), 385-404, 2000a.

Nemitz, E., Sutton, M. A., Schjoerring, J. K., Husted, S., and Wyers, G. P.: Resistance modelling of ammonia exchange over oilseed rape, Agr. For. Meteorol., 105, 405-425, 2000 b.

Nemitz, E., Sutton, M. A., Wyers, G. P., Otjes, R. P., Mennen, M. G., van Putten, E., Hellemond, J., and Gallagher, M. W.: Gasparticle interactions above a Dutch heathland: II. Concentrations and surface exchange fluxes of atmospheric particles, Atmos. Chem. Phys., 4, 1007-1024, 2004,

http://www.atmos-chem-phys.net/4/1007/2004/.

Nemitz, E., Hargreaves, K. J., Neftel, A., Loubet, B., Cellier, P., Dorsey, J. R., Flynn, M., Hensen, A., Weidinger, T., Meszaros, R., Horvath, L., Dämmgen, U., Frühauf, C., Löpmeier, F. J., Gallagher, M. W., and Sutton, M. A.: Intercomparison and assessment of turbulent and physiological exchange parameters of grassland, Biogeosciences, 6, 1445-1466, 2009, http://www.biogeosciences.net/6/1445/2009/.

Novak, M. D., Chen, W., Orchansky, A. L., and Ketler, R.: Turbulent exchange processes within and above a straw mulch part 1: mean wind speed and turbulent statistics, Agr. For. Meteorol., 102, 139-154, 2000.

Personne, E., Loubet, B., Herrmann, B., Mattsson, M. E., Schjoerring, J. K., Nemitz, E., Sutton, M. A. Cellier, P.: SURFATM$\mathrm{NH}_{3}$ : a model combining the surface energy balance and the bi-directional exchanges of ammonia applied at the field scale, Biogeosciences Discuss., 6, 71-114, 2009, http://www.biogeosciences-discuss.net/6/71/2009/.

Poggi, D., Katul, G., and Albertson, J.: Scalar dispersion within a model canopy: Measurements and three-dimensional Lagrangian models, Adv. Water Res.s, 29(2), 326-335, 2006.

Raupach, M. R.: A practical Lagrangian method for relating scalar concentrations to source distributions in vegetation canopies, Q. J. Roy. Meteorol. Soc., 115, 609-632, 1989a.

Raupach, M. R.: Applying Lagrangian fluid mechanics to infer scalar source distributions from concentration profiles in plant canopies, Agr. For. Meteorol., 47, 85-108, 1989b.

Raupach, M. R., Antonia, R. A., and Rajagopalan, S.: Rough-wall turbulent boundary layers, Appl. Mech. Rev., 44(1), 1-24, 1991.

Raupach, M. R., Finnigan, J. J., and Brunet, Y.: Coherent eddies and turbulence in vegetation canopies: the mixing layer analogy, Bound.-Lay. Meteorol., 78, 351-381, 1996.

Riedo, M., Milford, C., Schmid, M., and Sutton, M. A.: Coupling soil-plant-atmosphere exchange of ammonia with ecosystem functioning in grasslands, Ecol, Model., 158(1-2), 83-110, 2002.

Rinne, J., Taipale, R., Markkanen, T., Ruuskanen, T. M., Hellen, H., Kajos, M. K., Vesala, T., and Kulmala, M.: Hydrocarbon fluxes above a Scots pine forest canopy: measurements and modelling, Atmos. Chem. Phys., 7, 3361-3372, 2007, http://www.atmos-chem-phys.net/7/3361/2007/.

Rodean, H. C.: Stochastic Lagrangian Models of Turbulent Diffusion, Meteorol. Monographs, 26, Amer. Meteorol. Soc., Boston, MA, USA, 84 pp., 1996.

Sawford, B. L.: Lagragian statistical simulation of concentration mean and fluctuation fields, J. Appl. Metorol., 24(3), 1152-1166, 1995.

Shaw, R. H., Tavangar, J., and Ward, D. P.: Structure of the Reynolds stress in a canopy layer, J. Climate Appl. Meteorol., 22, 1922-1931, 1983.

Shaw, R. H., den Hartog, G., King, K. M., and Neumann, H. H.: Influence of foliar density and thermal stability on profiles of Reynolds stress and turbulence intensity in a deciduous forest, Bound.-Lay. Meteorol., 45, 391-409, 1988.

Shaw, R. H., Brunet, Y., Finnigan, J. J., and Raupach, M. R.: A wind tunnel study of air flow in waving wheat: two-point velocity statistics, Bound.-Lay. Meterol., 76, 349-376, 1995.

Stroud, C., Makar, P., Karl, T., Guenther, A., Geron, C., Turnipseed, A., Nemitz, E., Baker, B., Potosnak, M., and Fuentes, J. D.: Role of canopy-scale photochemistry in modifying biogenicatmosphere excahnge of reactive terpene species: Results from the CELTIC field study, J. Geophys. Res. 110, D017303, doi:10.1029/2005JD005775, 2005.

Sutton, M. A., Nemitz, E., Theobald, M. R., Milford, C., Dorsey, J. R., Gallagher M. W., Hensen, A., Jongejan, P. A. C., Erisman, J. W., Mattsson, M. E., Schjoerring, J. K., Cellier, P., Loubet, B., Roche, R., Neftel, A., Herrmann, B., Jones, S. K., Lehman, B. E., Horvath, L., Weidinger, T., Rajkai, K., Burkhardt, J., Löpmeier, F. J., and Dämmgen, U.: Dynamics of ammonia exchange with cut grassland: Strategy and implementation of the GRAMINAE Integrated Experiment, Biogeosciences, 6, 309-331, 2009a, http://www.biogeosciences.net/6/309/2009/.

Sutton, M. A., Nemitz, E., Milford, C., Campbell, C., Erisman, J. W., Hensen, A., Cellier, P., David, M., Loubet, B., Personne, E., Schjoerring, J. K., Mattsson, M., Dorsey, J. R., Gallagher, M. W., Horvath, L., Weidinger, T., Meszaros, R., Dämmgen, U., Neftel, A., Herrmann, B., Lehman, B. E., Flechard, C., and Burkhardt, J.: Dynamics of ammonia exchange with cut grassland: synthesis of results and conclusions of the GRAMINAE Integrated Experiment, Biogeosciences Discuss., 6, 1121-1184, 2009, http://www.biogeosciences-discuss.net/6/1121/2009/.

Vesala, T., Kljun, N., Rannik, Ü., Rinne, J., Sogachev, A., Markkanen, T., Sabelfeld, K., Foken, T., and Leclerc, M. Y.: Flux and concentration footprint modelling: State of the art, Environ. Poll., 152(3), 653-666, 2008.

Warland, J. S. and Thurtell, G. W.: A Lagrangian solution to the relationship between a distributed source and concentration profile, Bound.-Lay. Meteorol., 96(3), 452-471, 2000.

Wilson, J. D. and Flesch T. K.: Flow boundaries in random-flight dispersion models: enforcing the well-mixed condition, J. Appl. Meteorol., 32, 1695-1707, 1993.

Wilson, J. D., Ward, D. P., Thurtell, G. W., and Kidd, G. E.: Statistics of atmospheric turbulence within and above a corn canopy, Bound.-Lay. Meteorol., 16, 1198-1205, 1982.

Wohlfahrt, G.: Modelling fluxes and concentrations of $\mathrm{CO}_{2}, \mathrm{H}_{2} \mathrm{O}$ and sensible heat within and above a mountain meadow canopy: a comparison of three Lagrangian models and three parameterisation options for the Lagrangian time scale, Bound.-Lay. Meteorol., 113(1), 43-80, 2004.

Wohlfahrt, G. and Cernusca, A.: Momentum transfer by a mountain meadow canopy: a simulation analysis based on Massman's (1997) model, Bound.-Lay. Meteorol., 103(3), 391-407, 2002. 